\title{
JT/LJT Connector Insert Material Evaluation
}

\section{Volume 1-Interim Report}

\author{
Johnny R. F. Baca
}

\section{Prepared by}

Sandia National Laboratories

Albuquerque, New Mexico 87185 and Livermore, Callfornia 94550

for the United States Department of Energy

under Contract DE-ACO4-76DPOO789

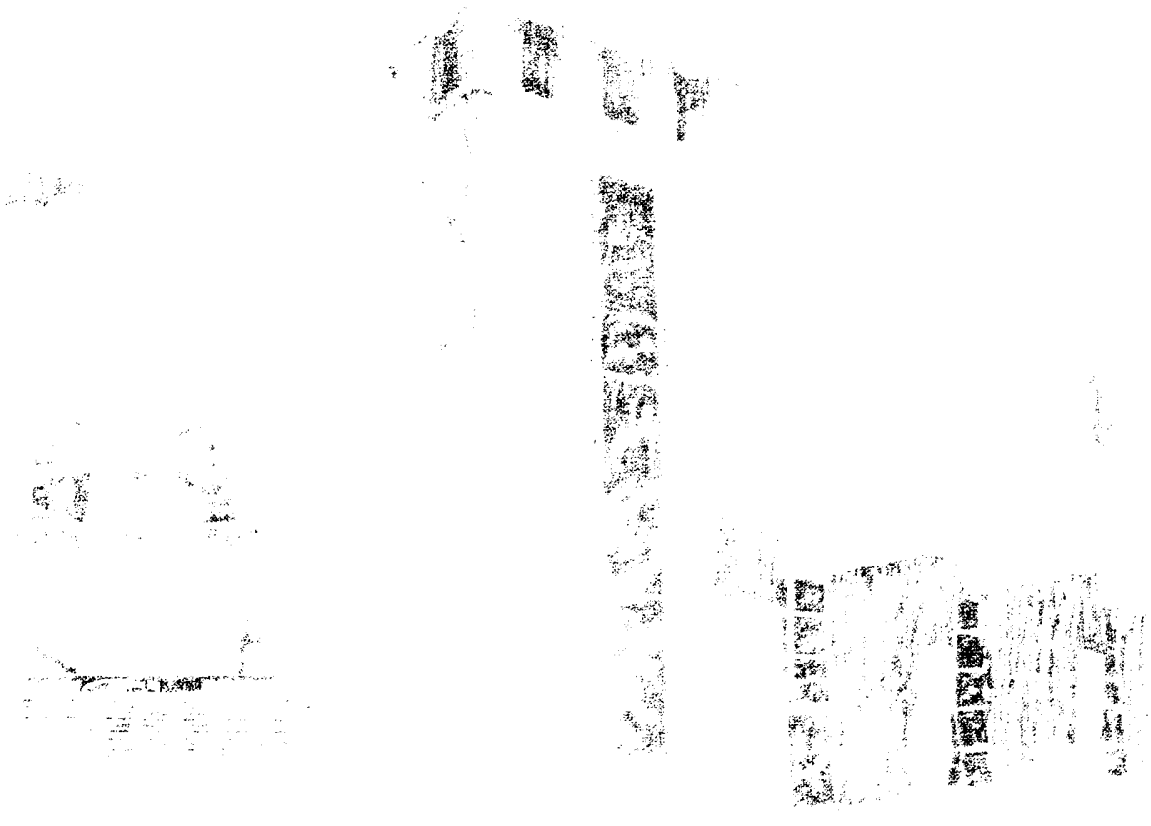


Issued by Sandia National Laboratories, operated for the United States Department of Energy by Sandia Corporation.

NOTICE: This report was prepared as an account of work sponsored by an agency of the United States Government. Neither the United States Government nor any agency thereof, nor any of their employees, nor any of their contractors, subcontractors, or their employees, makes any warranty, express or implied, or assumes any legal liability or responsibility for the accuracy, completeness, or usefulness of any information, apparatus, product, or process disclosed, or represents that its use would not infringe privately owned rights. Reference herein to any specific commercial product, process, or service by trade name, trademark, manufacturer, or otherwise, does not necessarily constitute or imply its endorsement, recommendation, or favoring by the United States Government, any agency thereof or any of their contractors or subcontractors. The views and opinions expressed herein do not necessarily state or reflect those of the United States Government, any agency thereof or any of their contractors.

Printed in the United States of America. This report has been reproduced directly from the best available copy.

Available to DOE and DOE contractors from

Office of Scientific and Technical Information

PO Box 62

Oak Ridge, TN 37831

Prices available from (615) 576-8401, FTS 626-8401

Available to the public from

National Technical Information Service

US Department of Commerce

5285 Port Royal Rd

Springfield, VA 22161

NTIS price codes

Printed copy: A04

Microfiche copy: A01 


\title{
JT/LJT Connector Insert Material Evaluation Volume 1-Interim Report
}

\author{
Johnny R. F. Baca \\ Connectors Division \\ Sandia National Laboratories \\ Albuquerque, NM 87185
}

\begin{abstract}
Different insert (insulator) materials are undergoing evaluation to replace the Fiberite E-3938 BE96 material currently used. Also being evaluated is the reconfiguration of the insert and metal shell-edge geometries for the purpose of reducing the alleged interference principally responsible for insert damage.
\end{abstract}




\section{Acknowledgments}

The author thanks Rudy N. Jaramillo (2855 at the time of this publication) for the illustrations, Roger L. Kurtz (2551) and Robert R. Evans (5126) for their testing support, and the many people within the Amphenol Corporation (BCO) and ICI Fiberite Corporation for their cooperation in providing information for this study. 


\section{Contents}

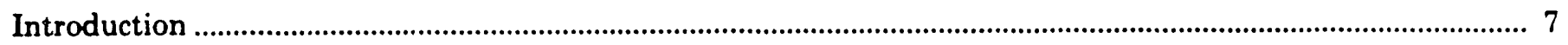

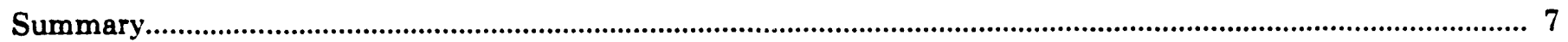

Candidate Materials and ICI Fiberite Recommendations ...................................................................................... 7

Description of Test Sample ................................................................................................................................... 8

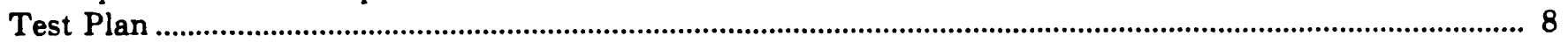

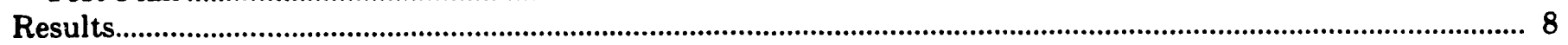

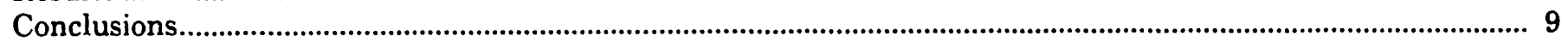

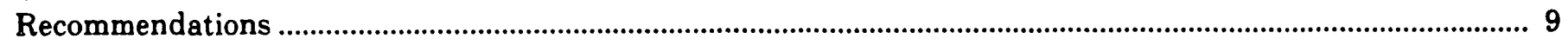

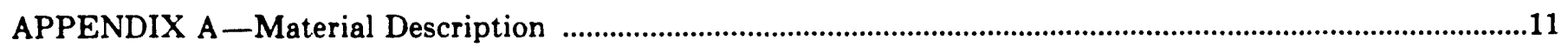

APPENDIX B-Insert Material Evaluation Test Plan …......................................................................................23

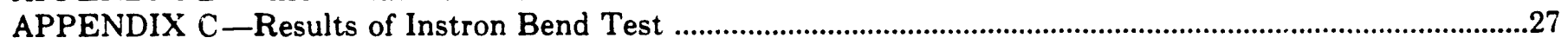

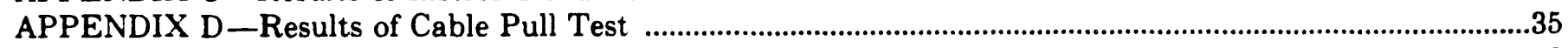

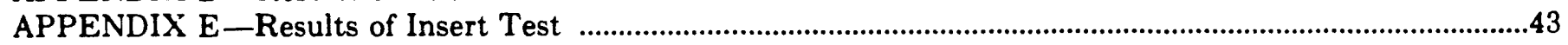

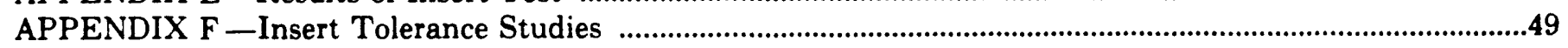

APPENDIX G-Configuration Studies and Tests ...................................................................................................53

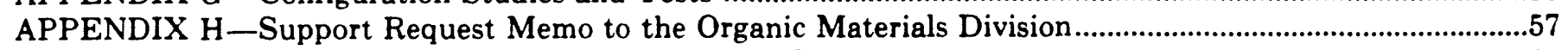

APPENDIX I - Memo to BCO Requesting Time and Cost Estimates ....................................................................61

APPENDIX J -BCO Material Evaluation Report .....................................................................................................65 


\section{JT/I_JT Connector Insert Material Evaluation}

\section{Volume 1-Interim Report}

\section{Introduction}

JT/LJT circular connectors have a rigid, hard dielectric insert of epoxy molding compound reinforced with long glass fibers. The insert material is a Fiberite E-3938 BE96 thermoset plastic. Pin and socket contacts in nonhermetic connectors are molded in place whereas hermetic connectors with socket contacts have an independent dielectric insert bonded to the glass header.

Forcing, twisting, jamming, and cocking of the mating halves of the connector may bend the exposed contacts, very often damage the insert, and damage the key or keyways on the connector shell.

There is a need to identify an insert material for both hermetic and nonhermetic circular connectors. The number of chipped and cracked connector inserts found in the field is significant enough to warrant a search for a replacement material. The material must be able to meet all the requirements currently in effect plus exhibit substantially improved resistance to damage such as chipping, cracking, etc. This evaluation program visits not only superior insert materials but improved connector designs as well to establish the best ingredients for surviving field-use environments. It is suspected that interference exists between the plug shell inner edge and the receptacle insert edge during separation, and that this is the principal cause of damage. Connector design improvements being considered include the redesign of edge geometries to relieve the alleged interference.

Included with this interim report are the following appendixes: Appendix A describes the materials evaluated and Appendix $B$ the evaluation test plan; Appendix $C$ reports on the results of the Instron bend test, Appendix D gives the results of the cable pull test, and the results of the insert test are given in Appendix E; Appendix $F$ discusses the insert tolerance studies and Appendix $G$ the configuration studies; a copy of the support request memo to the Organic Materials Division is presented in Appendix $\mathrm{H}$, and a memo to $\mathrm{BCO}$ requesting estimates is given in Appendix I; Appendix J contains the $\mathrm{BCO}$ material evaluation report.

A Final Report, Volume 2, will follow this Interim Report upon completion of this evaluation. The final report will identify the selected replacement insert material, explain the selection process, and summarize the test results.

\section{Summary}

The Connector Division (2551) placed a contract with Amphenol Corporation (BCO) for $\$ 69,574$ to fabricate and test $168 \mathrm{LJT} 07 / \mathrm{LJT} 07 \mathrm{H}-17-26 \mathrm{~S}$ connectors, report their findings, and identify a replacement insert material. Two smaller orders, totaling approximately $\$ 2500$, were also placed with BCO to mold and deliver 72 hermetic connector inserts of candidate materials including the current Fiberite E-3938 BE96 material. BCO is also asked to provide time and cost estimates for converting tooling and processes for three candidate materials.

We requested the ICI Fiberite Corporation to recommend a replacement for Fiberite E-3938 BE96; their recommendations have been received.

Personnel in the Organic Materials Division (2472) were asked for support in selecting an insert material. Product data sheets for the candidate materials and recommended Fiberite materials were provided.

Insert tolerance studies and configuration studies and tests were done in conjunction with the insert material studies.

\section{Candidate Materials and $\mathrm{ICl}$ Fiberite Recommendations}

Appendix A describes the material properties for each of the candidate materials and the ICI Fiberite Corporation recommended materials.

- Fiberite E-7459-16612 epoxy resin thermoset material. This is a proven material; it has been used in rack and panel connectors for WR use since March 1981. 
- Fiberite E264H epoxy resin thermoset material, recommended by Hugh A. Kearney of BCO.

- Torlon 4203L thermoplastic material, also recommended by Hugh A. Kearney of BCO.

- Fortron 1140L4 thermoplastic, recommended by Richard W. Normann of BCO. This is a proven material used for front socket inserts in MIL-C-38999 crimp removable connectors. This material is very affordable and readily available.

- PEEK RTP2205 thermoplastic, endorsed by R. Gordon Wheeler of BCO.

- Thermoset plastics recommended by ICI Fiberite Corporation:

Fiberite E8354-19189

Fiberite TEM 9001

Fiberite TEM 9010

Fiberite TEM 9025

\section{Description of Test Sample}

One way to alleviate the interference between the insert and plug shell is to "radius" the insert edge. Since this would require tooling modifications, Hugh A. Kearney of BCO suggested that a $30^{\circ}$ bevel be ground at the insert edge.

The test sample connectors ordered through BCO included design features such as different insulator (insert) materials, $30^{\circ}$ beveled edge and standard $90^{\circ}$ edge inserts for edge effects studies, and aluminum (standard) and stainless-steel (hermetic) shells.

Half of the hermetic connector inserts provided by $\mathrm{BCO}$ had $30^{\circ}$ beveled edges, the other half had standard $90^{\circ}$ edges.

\section{Test Plan}

The test plan was to subject the connector samples to Instron bend tests and cable pull tests to (1) evaluate the insert materials' resistance to fracture due to interference-induced stress and impact and (2) evaluate the benefits of beveling or rounding the insert edge.

We tested the hermetic connector inserts to determine which material was most resistant to fracture at the 0.031 -in.-thick contact aligning web.

\section{Results}

Damage assessment on connector and individual insert samples was made using the naked eye and $7 \mathrm{X}$ magnification. All connector and individual insert samples with ground $30^{\circ}$ beveled edges were inspected under magnification for voids, inclusions, filler material protrusions, etc. The ground surfaces in all candidate material samples exhibited only a roughness, compared to the molded surface; no other shortcomings were noted. Dave Zamora (2472) was consulted about the susceptibility of the ground surface in thermoset materials to moisture, Trichlor, alcohol, etc. Although no mold release is used with Fiberite materials, the molded surface appears to have a protective film compared to the ground surface but, nonetheless, Zamora assures us that the ground surface is no more susceptible than the molded surface. This is confirmed by the fact that molding sprues and Mashing along the skirt area in rack and panel connectors are cut and ground off, leaving exposed ground surfaces.

Fiberite E-7459-16612 performed well even in the unchamfered condition. This proven material uses almost the same molding pressures as Fiberite E-3938 BE96. Four-cavity molds are currently used, and they can be used for E16612 except when molding an overly staged batch of material requiring higher pressures, which reduces capacity to three cavities. This material would require virtually no change in molding processes, p:ocedures, or equipment. It has been molded in riouble-density and standard-density rack and panel connectors using size 22 contacts and size 20 contacts, respectively. The material costs about $22 \%$ more than the material currently used.

Fiberite E264H performed well even in the unchamfered condition; however, the connectors tested were in the hermetic configuration, which proved inadequate as test samples because the insertto-glass header bond broke loose in most cases. In addition, abrasive wear is shown on the stainless-steel core pins used to create the contact cavities because of the high molding pressures required, so the use of E264 H is being discouraged by $\mathrm{BCO}$. Also, the standard configuration connectors using E264H could not be molded because the molded-in contacts were being damaged from the high molding pressures, and mold cavities would not fill.

The same problems and concerns experienced with Fiberite E264H apply to Torlon 4203L, except that Torlon is injection-molded by a vertical load mold. New molds and a new press would be needed. A true-blood shuttle (i.e., robotic/automated assembly line) would be required to maintain the 30 -second findings (interval between injections).

Fortron 1140L/ performed the best. Under magnification, mold flash, or plastic flow caused by Instron and cable-pull testing, is visible, but the damage otherwise is nil. Fortron, an improved PPS (polyphenylene sulfide) resin, is tougher than conventional PPS, which means that it is less brittle in 
thin-wall sections. Tests are underway at All-Tech to determine whether Fortron can withstand WR environments, since brittleness is a weakness in conventional PPS. The twelve test samples previously subjected to Instron or cable-pull testing will be subjected to the following test plan:

- Insulation resistance (IR)

- Dielectric withstanding voltage (DWV)

- Contact resistance (CR)

- Temperature cycle: $-65^{\circ} \mathrm{C}$ to $+177^{\circ} \mathrm{C}$

- Mechanical shock: $3500 \mathrm{~g}$ at $1 \mathrm{~ms}$ and $4500 \mathrm{~g}$ at 0.2 to $0.5 \mathrm{~ms}$, both directions in all three axes

- Random vibration: $33 \mathrm{~g} \mathrm{rms}, 10$ to $2500 \mathrm{~Hz}$.

Ten of the twelve test samples of the Fortron hermetic connector inserts will be subjected to a mechanical shock of $4500 \mathrm{~g}$ at $0.3 \mathrm{~ms}$, both directions in all three axes.

$\mathrm{BCO}$ has not yet fabricated or tested the PEEK RTP2205 connector samples. This is a thermoplastic with good thermal, mechanical, and electrical characteristics. BCO uses carbon-filled (45\% carbon fiber) PEEK in its composite connectors. R. Gordon Wheeler endorses the PEEK grade selected and suggests that PEEK is the material for the Sandiadesigned product. Time and cost estimates from $\mathrm{BCO}$ are crucial to feasibility studies, but a reply has not yet been received.

Configuration studies and tests have demonstrated that reconfiguring the metal shells and inserts to alleviate interference may not be cost-effective, considering the magnitude of the interference in question. Results of insert tests showed that Fortron has the greatest mechanical strength, Torlon and Fiberite E264H are most severely affected by moisture and temperature changes, and Fiberite E-7459. 16612 is very stable, though not exceptionally strong. Instron bend tests and cable-pull tests showed Fortron to be the superior material; it incurred no damage. Chamfered inserts of all the candidate materials tested provided good resistance to damage.

\section{Conclusions}

1. Torlon 4203L and Fiberite E264H require molding pressures so great that both the stainless-steel core pins used in molding hermetic inserts and the molded-in contacts in standard connectors are being damaged.

2. A superior insert material is required to optimize chipping resistance without altering the connector design. Reconfiguration of the insert and metal shell geometries would pro- vide interference relief but would not eliminate the insert chipping problem.

3. Insert fracture or chipping is more likely caused by impact than by interferenceinduced stress (bending).

4. Test results demonstrated that a $30^{\circ}$ bevel on the insert's outer edge reduces edge chipping by $75 \%$.

5. Connectors with thermoplastic inserts exhibited no damage, whereas those with Fiberite (thermoset) inserts experienced some degree of damage in most cases. The best performing insert material was Fortron, a thermoplastic.

6. Materials exhibiting the greatest change due to temperature cycling and humidity were Torlon and Fiberite E264H. Fiberite E264H and E-7459-16612 exhibited equal strength after simulated environmental exposure. Fortron exhibited the greatest strength overall. PEEK inserts have not been received yet; hence, we have no test results.

\section{Recommendations}

Fortron should be considered as a serious candidate, and should be evaluated further.

Although we have not received the test samples yet, PEEK also deserves serious evaluation.

Fiberite E-7459-16612 should be the 'hermoset plastic most seriously considered. Test results showed a marked improvement over the currently used Fiberite E-3938 BE96. Molding pressures are nearly identical and molding processes would remain unchanged. Molds may require slight modifications because of differences in shrinkage rates. As an epoxy resin thermoset plastic, it is compatible with the Dow Corning Q3-6611 silicone adhesive (and its alternate, AF-163-2K epoxy) that $\mathrm{BCO}$ is proposing to use to bond epoxy inserts to glass headers in hermetic connectors.

Ken Wischmann (2472) lent his support in selecting a new insert material. Ken contacted ICI Fiberite Corporation and is supporting their recommendation to use Fiberite E-8354-19189 or Fiberite TEM-9001.

Of the four thermoset materials recommended by ICI Fiberite, Fiberite TEM-9001 appears to be the most promising. Its impact and flexural strength properties are superior to Fiberite E-3938 BE96 and E-7459-16612. It can be transfer-molded at almost the identical pressures now used, and its shrinkage rate is comparable to Fiberite E-3938 BE96. The benefits described above for Fiberite E-7459-16612 also apply. Good second-choice materials are E-8354-19189 and 
E-7459-16612. But both are based on 20-year-old technology, except for an improved resin matrix in E-8354-19189.
Impact and flexural strength properties should be major considerations in the material selection. 


\section{APPENDIX A}

\section{Material Description}




\section{Materials Under Evaluation}

Table A-1 lists the properties (manufacturers' data) for each of the following materials:

Fiberite E-3938 BE96 - a high-temperature, mediumimpact glass fiber-filled thermoset plastic consisting of $30 \%$ epoxy resin and $70 \% 1 / 8$-in.-long glass fibers. This medium-flow epoxy molding compound exhibits good mechanical and electrical properties with low bulk factor. It is suitable for continuous exposure to temperatures approaching $232^{\circ} \mathrm{C}\left(450^{\circ} \mathrm{F}\right)$.

(ICI Fiberite Corp., Winona, MN)

Fiberite E-7459-16612-a high-temperature, mediumstrength glass fiber-reinforced thermoset plastic consisting of $60 \%$ epoxy resin and $40 \% 1 / 4$-in.-long glass fibers. This epoxy molding compound has good electrical and strength properties and is suitable for continuous exposure to temperatures approaching $232^{\circ} \mathrm{C}\left(450^{\circ} \mathrm{F}\right)$. It also features good flow and fast cure properties with excellent release.

(ICI Fiberite Corp., Winona, MN)

Fiberite E264H-a high-temperature, high-strength glass fiber-reinforced thermoset plastic consisting of $40 \%$ epoxy resin and $60 \%$ 1/4-in.-long glass fibers. This epoxy molding compound is suitable where good electrical and mechanical performance is required. In addition to its high mechanical properties, this product exhibits good molding characteristics for compression and transfer molding and is suitable for continuous exposure to temperatures approaching $232^{\circ} \mathrm{C}$ $\left(450^{\circ} \mathrm{F}\right)$.

(ICI Fiberite Corp., Winona, MN)

Torlon 4203L - an unreinforced thermoplastic. This polyamide-imide molding compound contains a small amount of fluorocarbon molding aid and titanium dioxide, but no other reinforcement (no more than
$5 \%$ of other fillers or modifying material). It requires 72 hours of post-cure but exhibits extreme thermal and oxidative stability, exceptional solvent and radiation resistance, excellent electrical properties, and high strength and toughness. In addition, it is suitable for continuous exposure to temperatures approaching $260^{\circ} \mathrm{C}\left(500^{\circ} \mathrm{F}\right)$.

(Amoco Chemical Co., Alfreda, GA)

Fortron 1140L4-a polyphenylene sulfide (PPS), 40\% fiber glass, low flash grade thermoplastic. Fortron is an improved PPS resin. It has a lower level of ionic impurities, which means it is a purer, more consistent product. It is tougher than conventional PPS, i.e., less brittle in thin-wall sections. A high-performance crystalline material, Fortron offers an excellent combination of good processibility and superior thermal and mechanical properties. This material is ideal for applications that require high temperature stability, toughness, chemical resistance, inherent flame resistance, and good moldability. In addition, it is suitable for continuous exposure to temperatures approaching $220^{\circ} \mathrm{C}\left(428^{\circ} \mathrm{F}\right)$.

(Hoechst Celanese, Chatham, NJ)

PEEK RTP2205 - a polyetheretherketone, $30 \%$ fiber glass-reinforced thermoplastic. This material is a high-performance crystalline thermoplastic polymer combining the chemical and thermal properties of some thermosets and ease of processibility. PEEK was developed for high-performance stringent requirements with respect to heat resistance, flammability, products of combustion, and chemical resistance. It is suitable for processing by extrusion or injection molding and for continuous exposure to temperatures approaching $220^{\circ} \mathrm{C}\left(428^{\circ} \mathrm{F}\right)$.

(RTP Co., Winona, MN) 


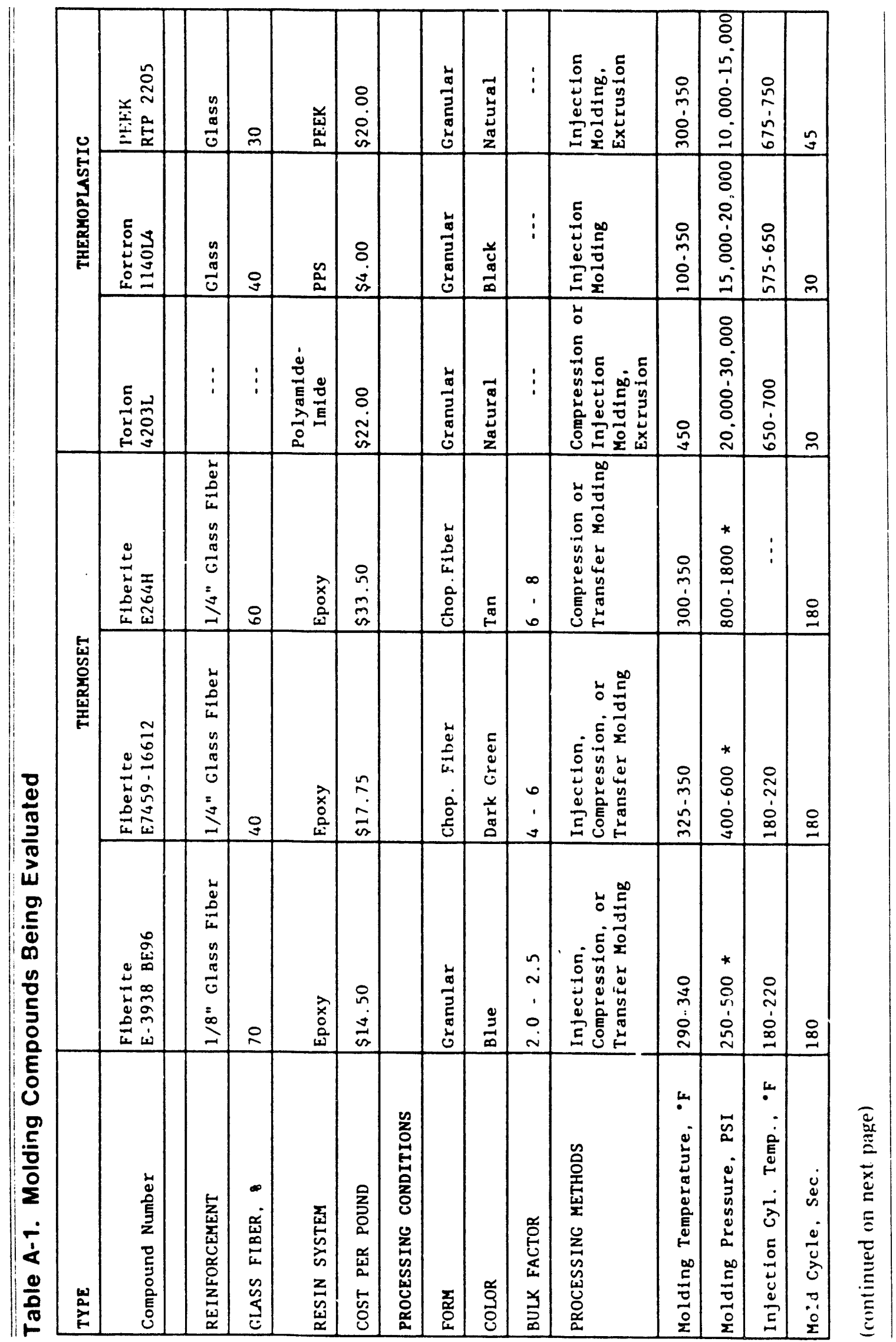




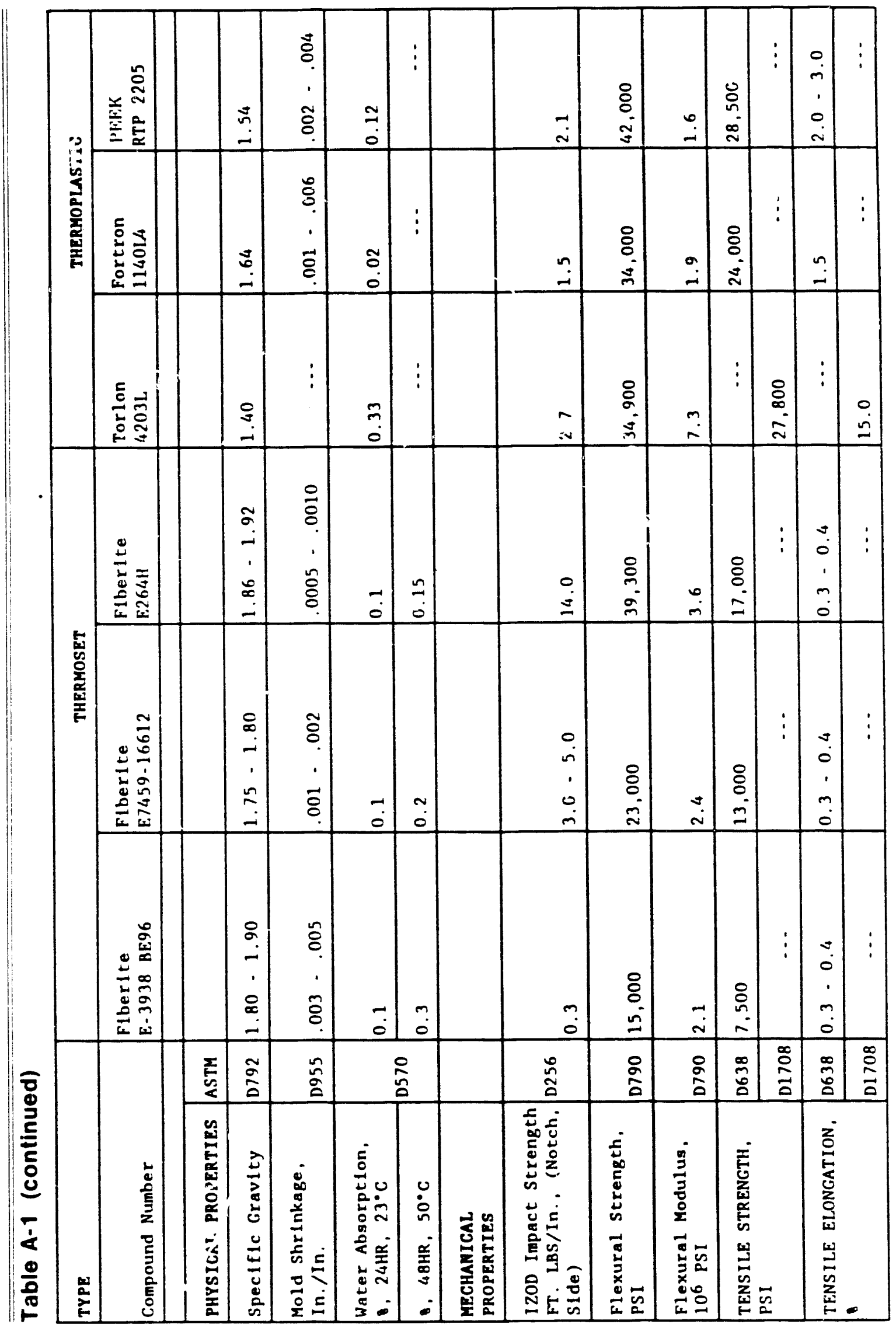

咅 


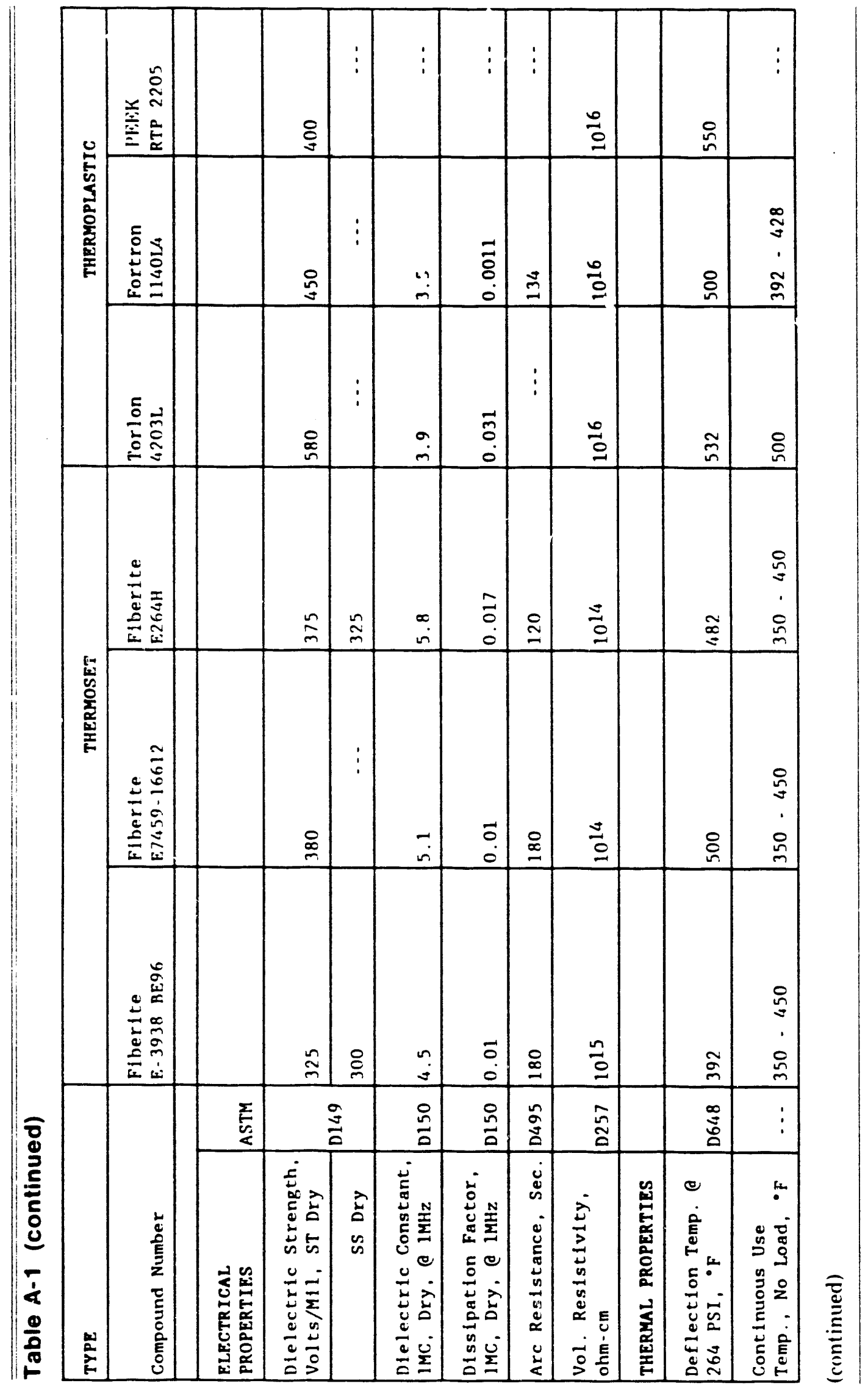




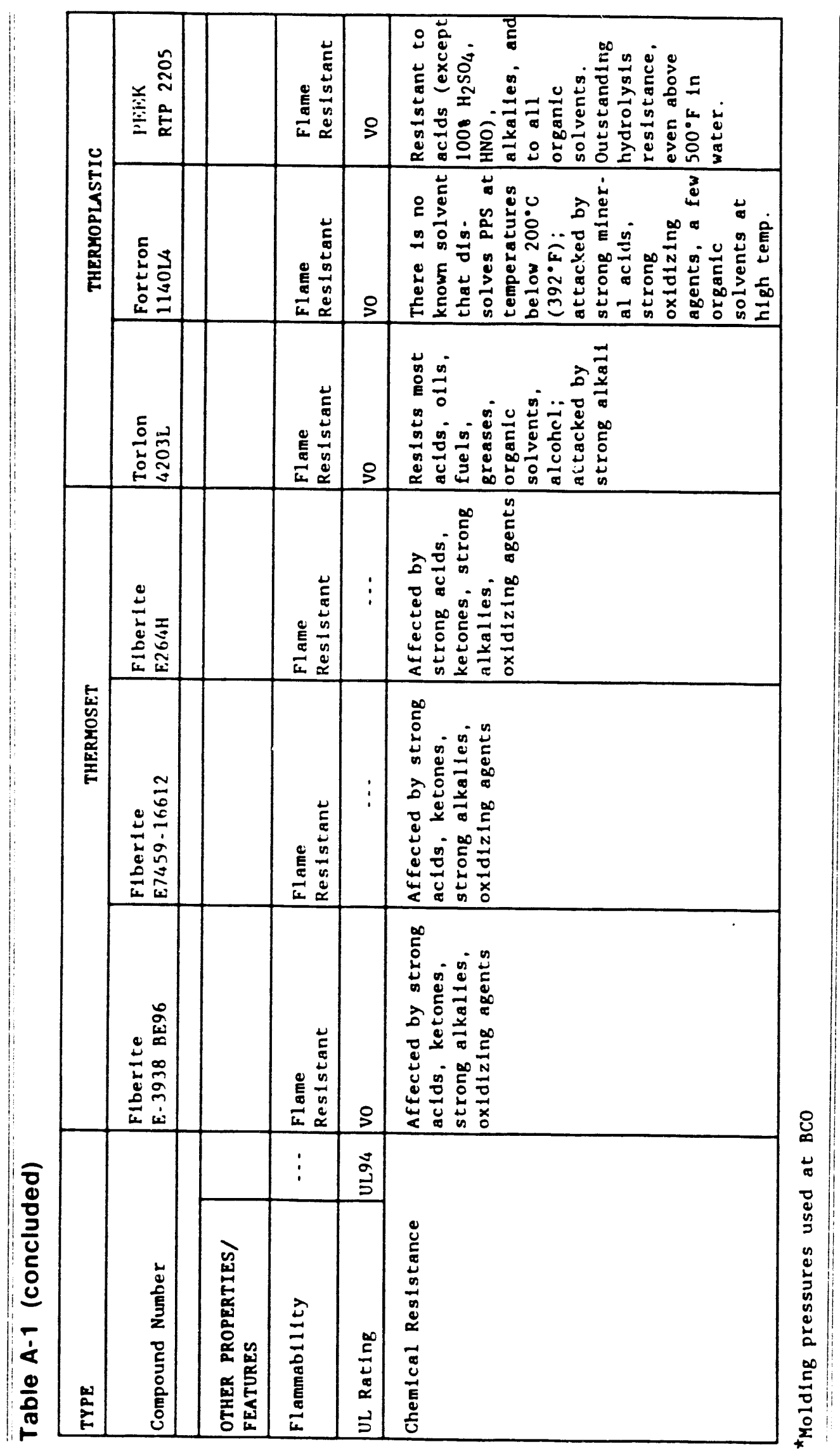




\section{Materials Recommended by $\mathrm{ICl}$ Fiberite Corporation}

Table A-2 lists the properties (manufacturers' data) for each of the following materials:

Fiberite E-8354-19189-a thermoset plastic having a resin matrix much more resistant to chipping than the thermoset materials listed in Table A-1. It has a nontoughened epoxy resin but is a much improved material, although based on old technology similar to Fiberite E-3938 BE96. It also molds like Fiberite E-3938 BE96 with perhaps a molding pressure change.

(ICI Fiberite Corp., Winona, MN)

Fiberite TEM 9001-a thermoset plastic with a toughened epoxy resin and glass/mineral reinforcement. This material is superior to thermoplastics many times over, and maintains better dimensional stability. It is used in applications requiring greater toughness and strength.

(ICI Fiberite Corp., Winona, MN)
Fiberite TEM 9010-a thermoset plastic with a toughened epoxy resin and glass/mineral reinforcement. This material also is superior to thermoplastics and maintains better dimensional stability. It is replacing aluminum in many structural applications. It is ideal for applications requiring greater toughness and strength.

(ICI Fiberite Corp., Winona, MN)

Fiberite TEM 9025-a high-strength thermoset plastic with a toughened epoxy resin system and $1 / 2$-in.long ( $1 / 4$ in. available) E-glass reinforcement. This compound offers substantial improvements in strength and toughness over other conventional glass fiber epoxy molding compounds. It is superior to thermoplastics in many cases, and maintains better dimensional stability. It should be used as a replacement in applications using Fiberite E264H.

(ICI Fiberite Corp., Winona, MN) 


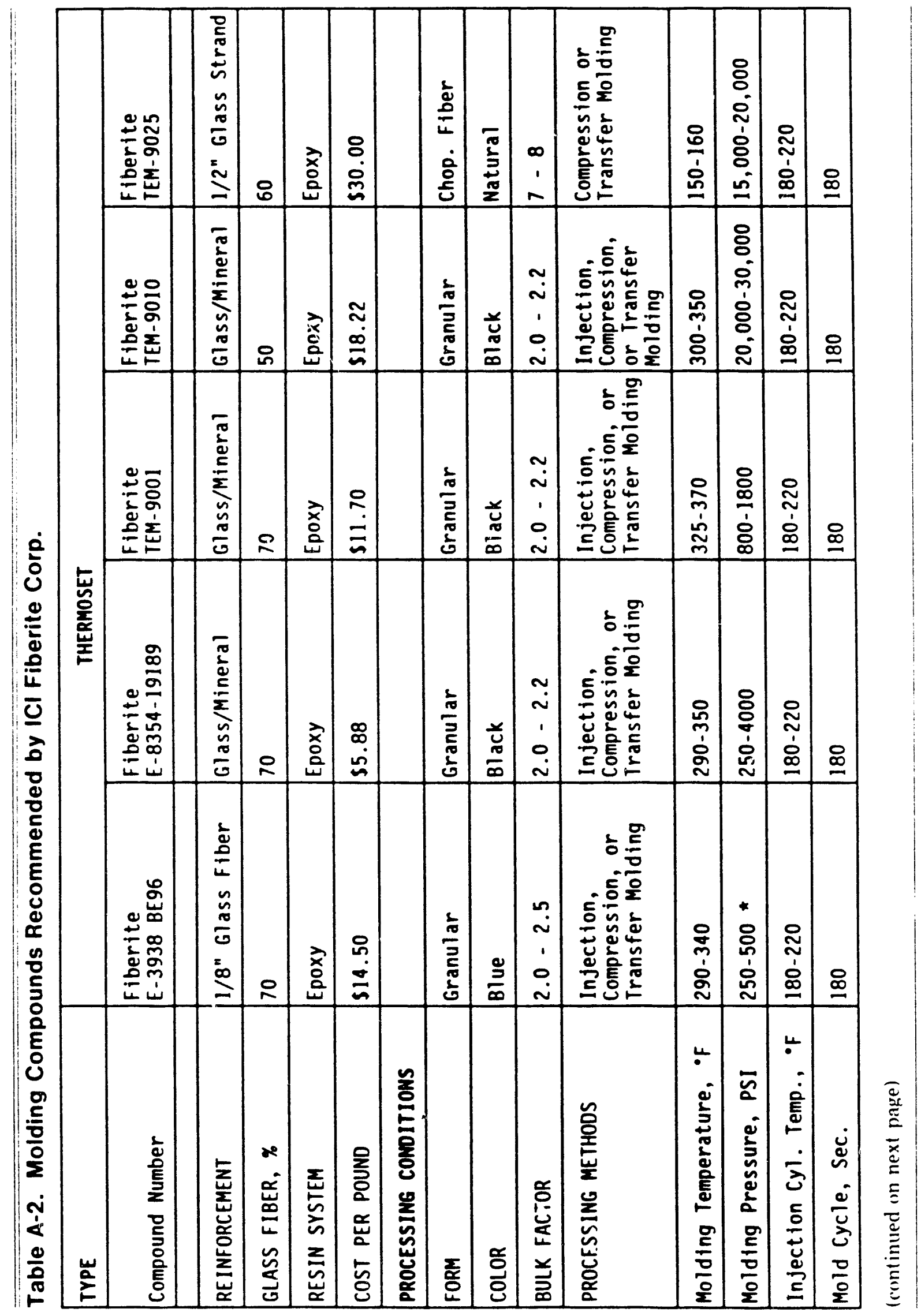




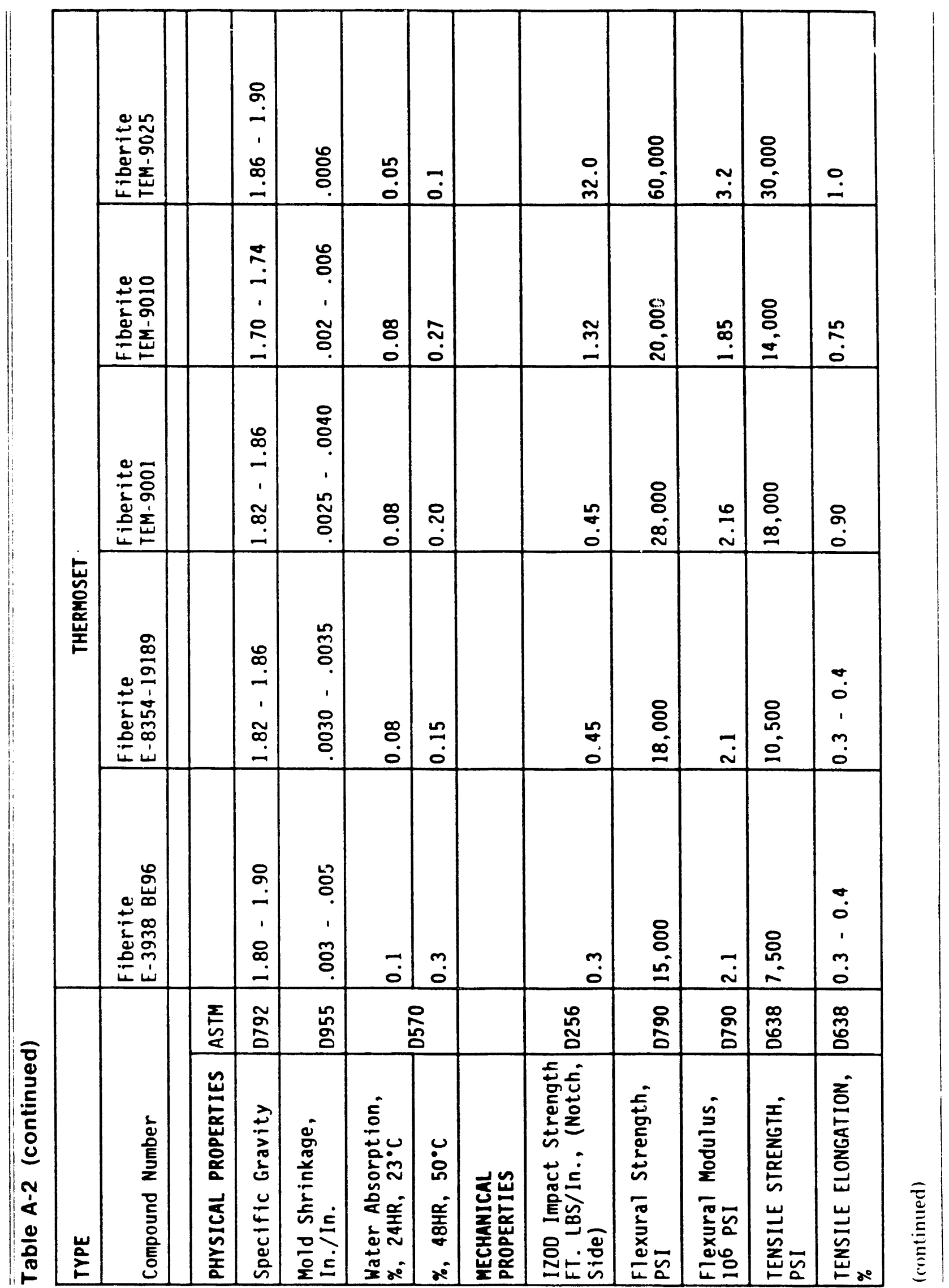




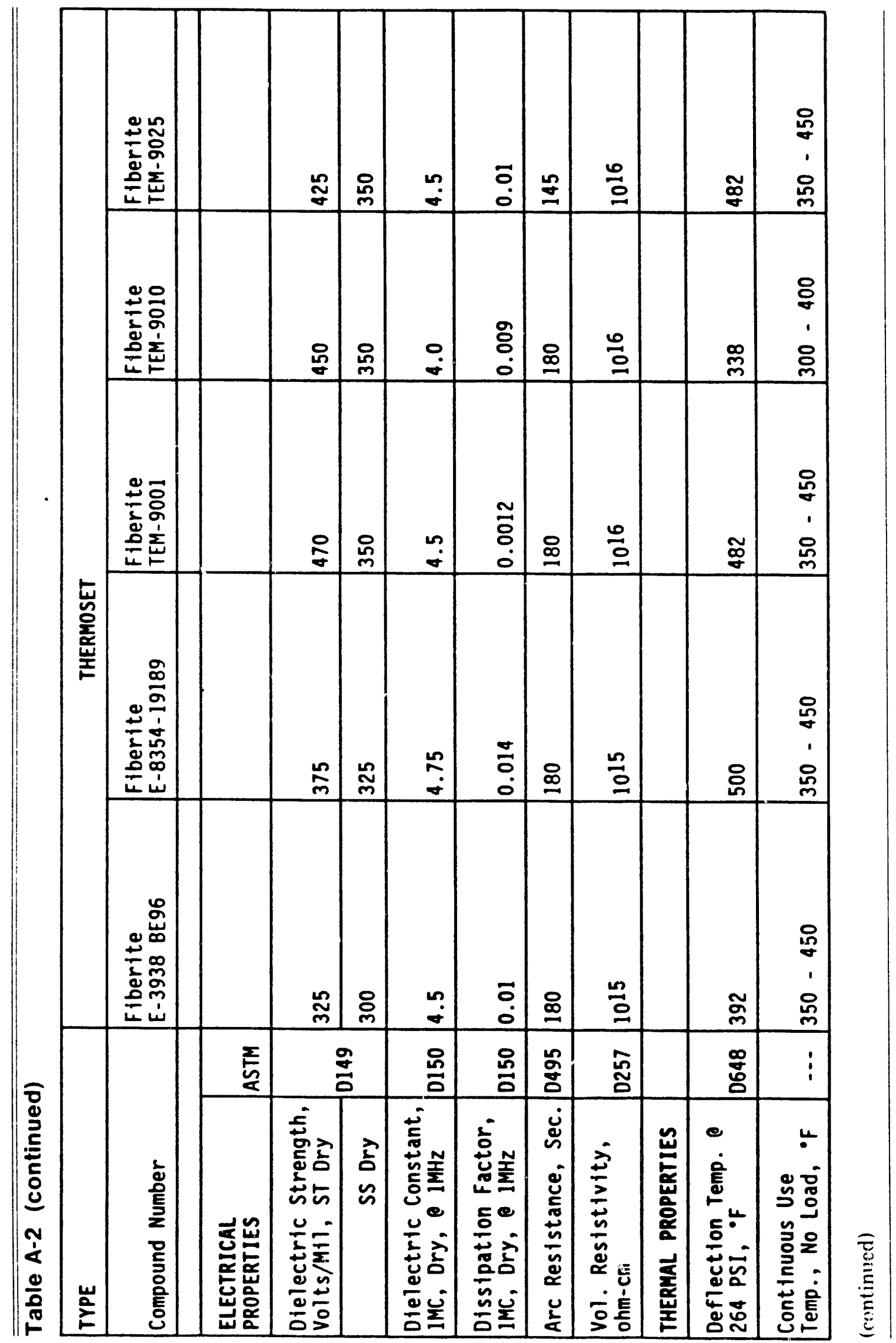




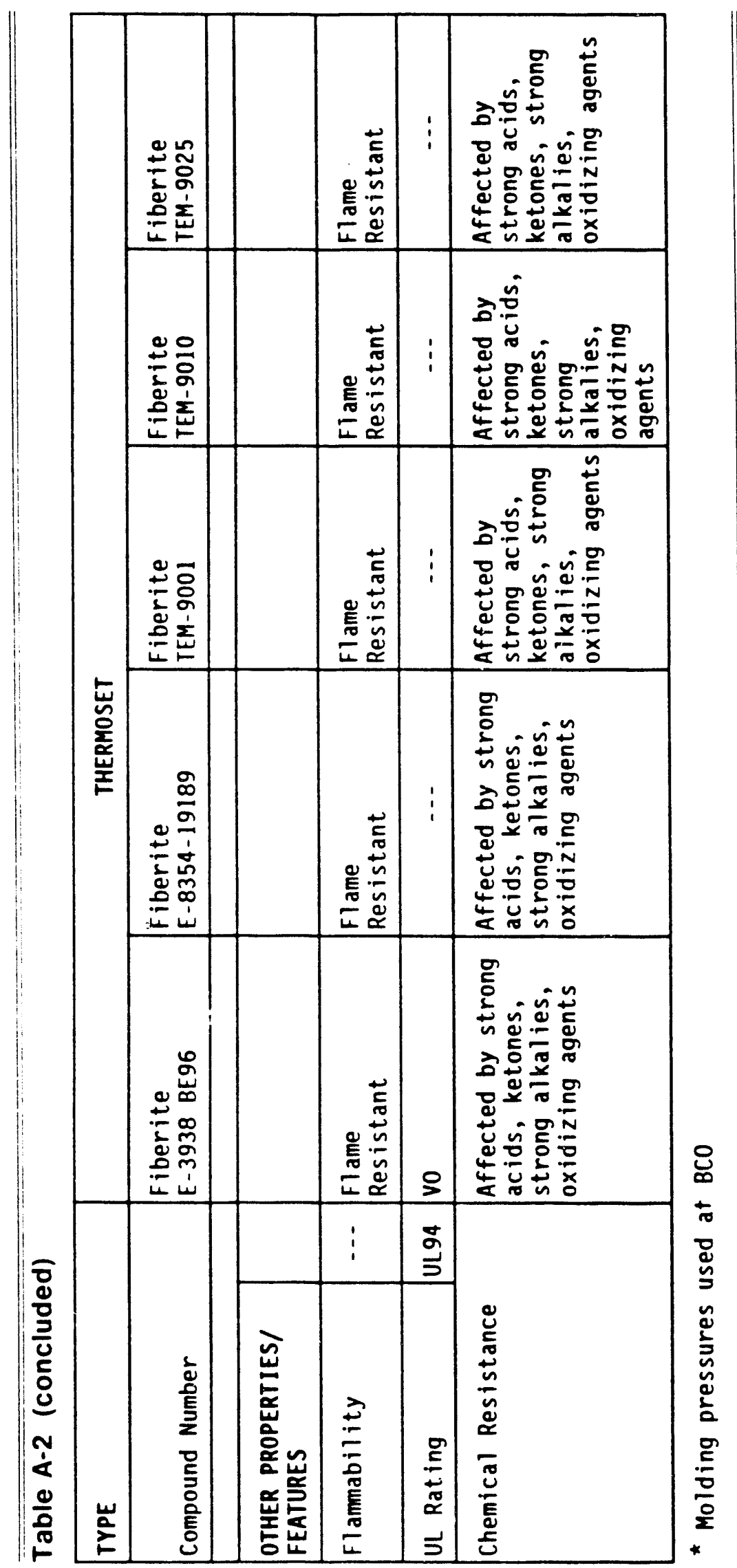




\section{APPENDIX B}

\section{Insert Material Evaluation Test Plan}




\section{Test Plan}

Purchase Order 40-9343 requires that BCO provide the following:

168 connectors total:

84 hermetic connectors (SA1457-1, LJT07H$17-26 \mathrm{~S}$ receptacle)

14 with sharp-edge inserts of Fiberite E-3938 BE96

14 with $30^{\circ}$ chamfered-edge inserts of Fiberite E-3938 BE96

14 with sharp-edge inserts of Fiberite $\mathrm{E} 264 \mathrm{H}$

14 with $30^{\circ}$ chamfered-edge inserts of Fiberite E264H

14 with sharp-edge inserts of Torlon 4203L

14 with $30^{\circ}$ chamfered-edge inserts of Torlon 4203L

84 standard connectors (SA1442-2, LJT07-17$26 \mathrm{~S}$ receptacle)

14 with sharp-edge inserts of Fiberite E-3938 BE96

14 with $30^{\circ}$ chamfered-edge inserts of Fiberite E-3938 BE96

*14 with sharp-edge inserts of Fiberite E264H

* 14 with $30^{\circ}$ chamfered-edge inserts of Fiberite E264H

*14 with sharp-edge inserts of Torlon 4203L

* 14 with $30^{\circ}$ chamfered-edge inserts of Torlon 4203L

Molding trials with Torlon 4203L and Fiberite E264 H in the standard connector configuration were unsuccessful because the high pressures required damaged the molded-in contacts.

$\mathrm{BCO}$ was required to perform the following tests (descriptions follow) on all of the 168 connectors, and document the results.

- Hi-Pot (DWV)

- Insulation Resistance

- Leak Check (VEECO) with data recorded

Subsequently, 72 connectors (6 from each group) were tested as follows:

- Visual examination of inserts

- Instron bend test (Figure B-1)

-Fiberite E-7459-16612 was substituted for Fiberite E264H. At $\mathrm{BCO}$ 's recommendation, Fortron $1140 \mathrm{~L} 4$ was substituted for Torlon $4203 \mathrm{~L}$
- Hi-Pot (DWV)

- Insulation Resistance

- Leak Check (VEECO) with data recorded

- Visual examination of inserts

A report was submitted at the conclusion of these tests.

The remaining 96 connectors were delivered to the Connectors Division (2551) for testing.

Upon completion of the contract, BCO will deliver:

- The remaining 72 tested connectors

- Three mating shells for SNL testing

- A report of all findings

To date, $\mathrm{BCO}$ has delivered 151 connectors tested, as required, at a cost of $\$ 30,030.89$. Seventeen remain delinquent; they are:

8 standard connectors with sharp-edge inserts of Fortron 1140L4

8 standard connectors with $30^{\circ}$ chamfered-edge inserts of Fortron 1140L4

1 hermetic connector with $30^{\circ}$ chamfered-edge insert of Torlon 4203L

Purchase Order $40-9343$ authorized $\$ 69,574$ for the insert material evaluation. After the remaining 17 connectors are received, enough money will be left over for continued evaluation. BCO has been requested to amend the existing purchase order by adding the following standard-configuration connectors:

14 with sharp-edge inserts of PEEK RTP2205

14 with $30^{\circ}$ chamfered-edge inserts of PEEK RTP2205

This will increase the total required to 196 connectors: 84 to be tested by $\mathrm{BCO}$ and 112 to be delivered to Division 2551 for testing.

\section{Test Description}

\section{Hi-Pot (DWV):}

BCO Automatic Connector Tester F-2043

Room ambient conditions

Spec limits: no electrical breakdown or flashover at $1500 \mathrm{~V}$ ac

The socket receptacles are mated to a wired, pin test harness and subjected to the DWV as follows:

- The magnitude of the test voltage is $1500 \mathrm{~V}$ ac.

- The voltage is applied between each contact and all other contacts and the shell tied electrically in common for a minimum of $5 \mathrm{~s}$. 


\section{Insulation Resistance:}

BCO Automatic Connector Tester F-2043

Room ambient conditions

Spec limits:

$1 \mathrm{G} \Omega$ minimum at $500 \mathrm{~V}$ dc (hermetic)

$10 \mathrm{G} \Omega$ minimum at $500 \mathrm{Vdc}$ (non-hermetic)

The insulation resistance is measured on the socket receptacles by mating each to a pin test harness.

- The applied voltage for the IR measurements is $500 \mathrm{~V}$ dc.

- The voltage is applied to each circuit for a minimum of $5 \mathrm{~s}$, and the IR is measured between each circuit and all other circuits and the shell tied electrically in common.

\section{Leak Chieck:}

VEECO Helium Leak Detector

Spec limits: $1 \times 10^{-8} \mathrm{~cm}^{3} / \mathrm{s}$ for hermetic connectors
Spec limits: $1 \times 10^{-3} \mathrm{~cm}^{3} / \mathrm{s}$ for standard connectors

\section{Instron Bend Test: (Figure B-1)}

Instron PG-1050

Room ambient conditions

Limits and conditions: $270 \mathrm{in}$.- $\mathrm{lb}$ load applied to front edge of insert

The test samples are subjected to a bend test using a 270 in.-lb moment. A simulated plug shell, exclusive of keys and coupling ring to permit more uniform loading against the receptacle insert, is inserted into each receptacle to a depth of $0.25 \mathrm{in}$. A $110-\mathrm{lb}$ load is then applied to the plug fixture through a 2.47 -in. lever arm. The load is applied to the insert, at a rate of $1 \mathrm{in} . / \mathrm{min}$, in a direction that applies stress $180^{\circ}$ from the main keyway area of the receptacle insert. 


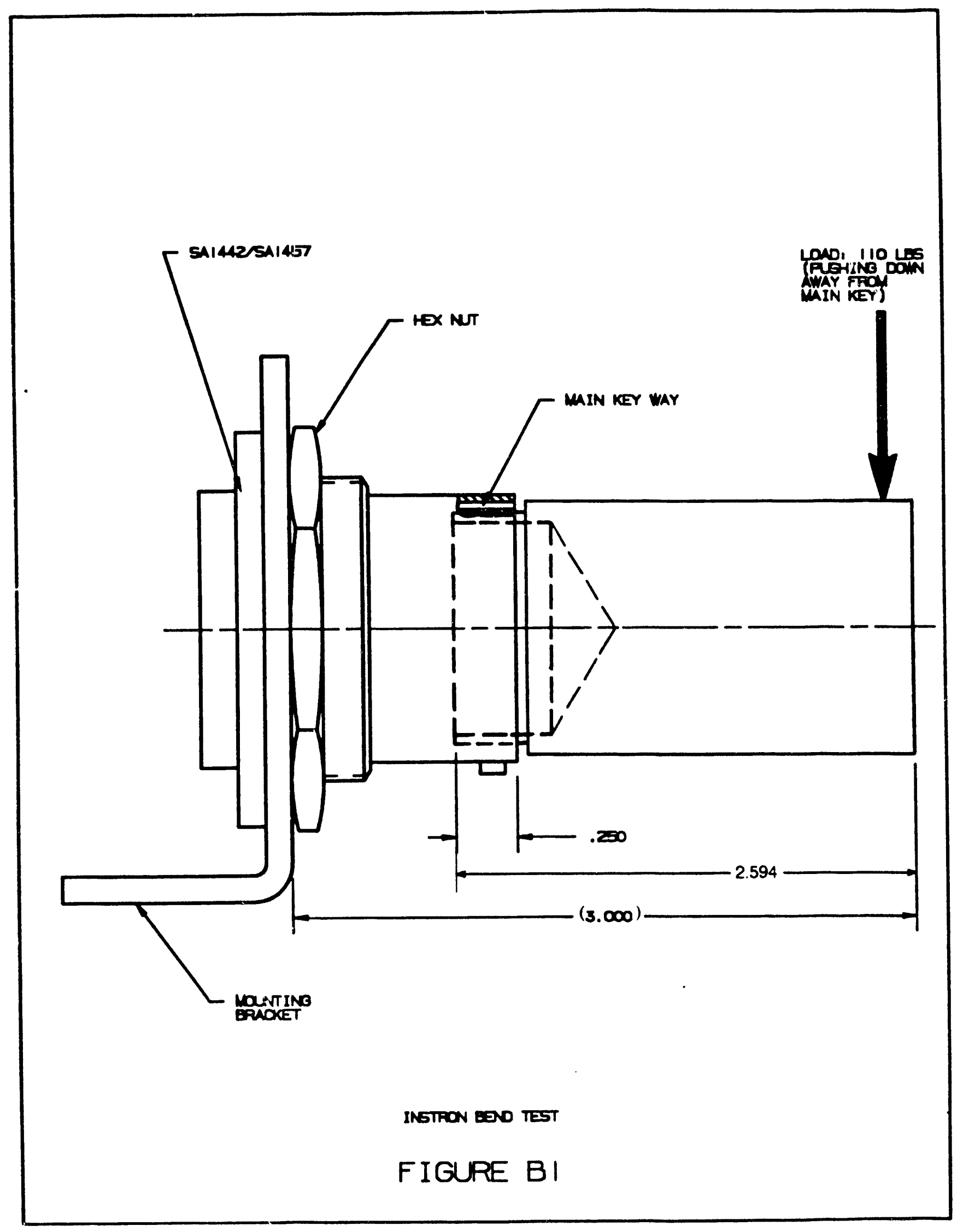




\section{APPENDIX C}

Results of Instron Bend Test 


\section{Summary}

The Connectors Division (2551) had BCO perform Instron bend tests on connectors of different insert materials and of different insert edge configurations. The Instron bend test provides a controlled and measurable $v_{\text {ray }}$ to fracture the insert. The level of insert damage sustained per connector is recorded in Table C-1 with examples of insert damage illustrated in Figure C-1. The tests were performed as described in the Insert Material Evaluation Test Plan (Appendix B).

The initial plan was to

1. Have BCO test six connectors from each group, per Statement of Work.

2. Subject the remaining connectors to humidity and temperature cycling, then have BCO Instron bendtest four from each group and subject the remaining four from each group to cable pull tests.

Exposure to humidity and temperature cycling was intended to replicate field environments.

\section{Results}

Damage ranged from no chipping to major chipping. Results of these tests also demonstrated that the $30^{\circ}$ bevel on the insert's outer edge reduces the amount of edge chipping that occurs. The hermetic connectors proved inadequate as test samples because the insert-to-glass header bond frequently broke loose during Instron bend tests. In cases where IR failures occurred with inserts seemingly intact after Instron testing, we speculated that the insert-to-glass header bond failed but did not separate completely. Visual damage assessment was made with both the naked eye and under $7 \times$ magnification.

\section{Conclusion}

Connectors with thermoplastic inserts exhibited no damage, whereas those with Fiberite (thcrmoset) inserts experienced some degree of damage in most cases. The best performing insert material was Fortron, a thermoplastic.

Although it is difficult to predict the reason damage occurred on some of the connectors, I believe that impact was the principal factor. In $90 \%$ to $95 \%$ of the cases, damage occurred in the main kevway area, which is $180^{\circ}$ from the area being stressed. This leads me to believe that damage is occurring at the moment that the simulated plug shell slips off the receptacle shell (test sample) and bangs into the insert. The area being stressed is experiencing more interference than normal since the simulated plug shell is devoid of keys and coupling ring; yet, it is showing minimal damage. 


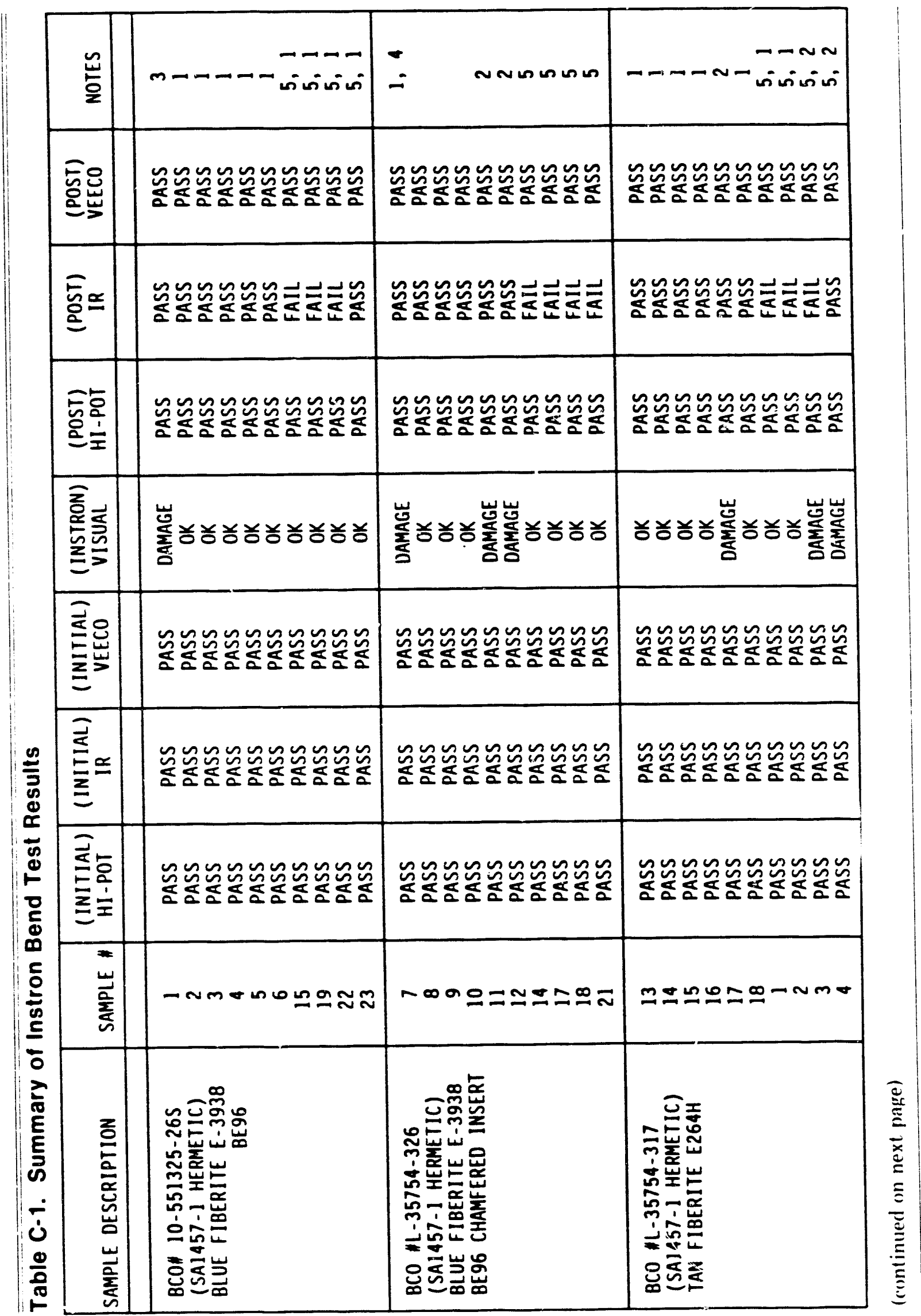




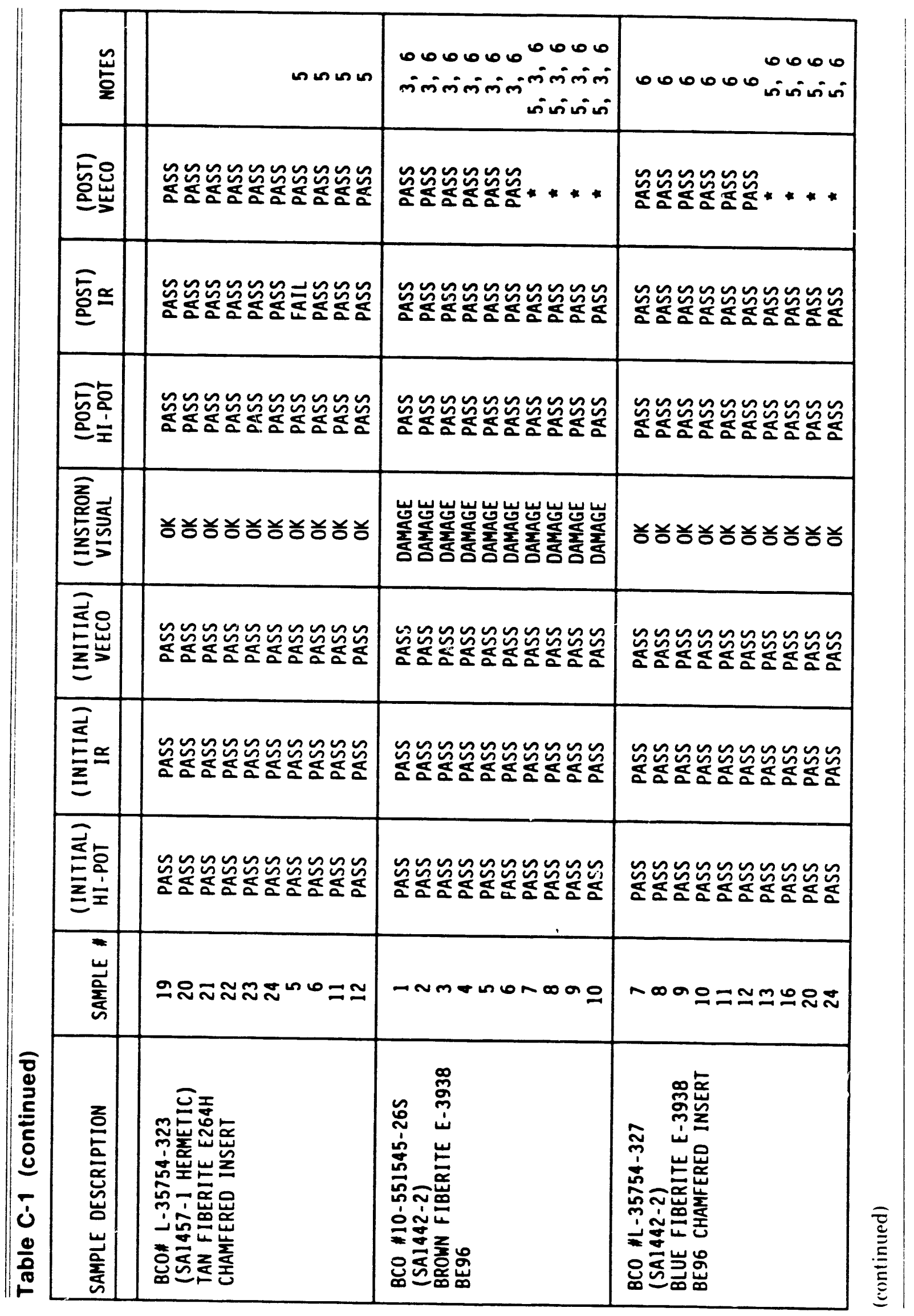




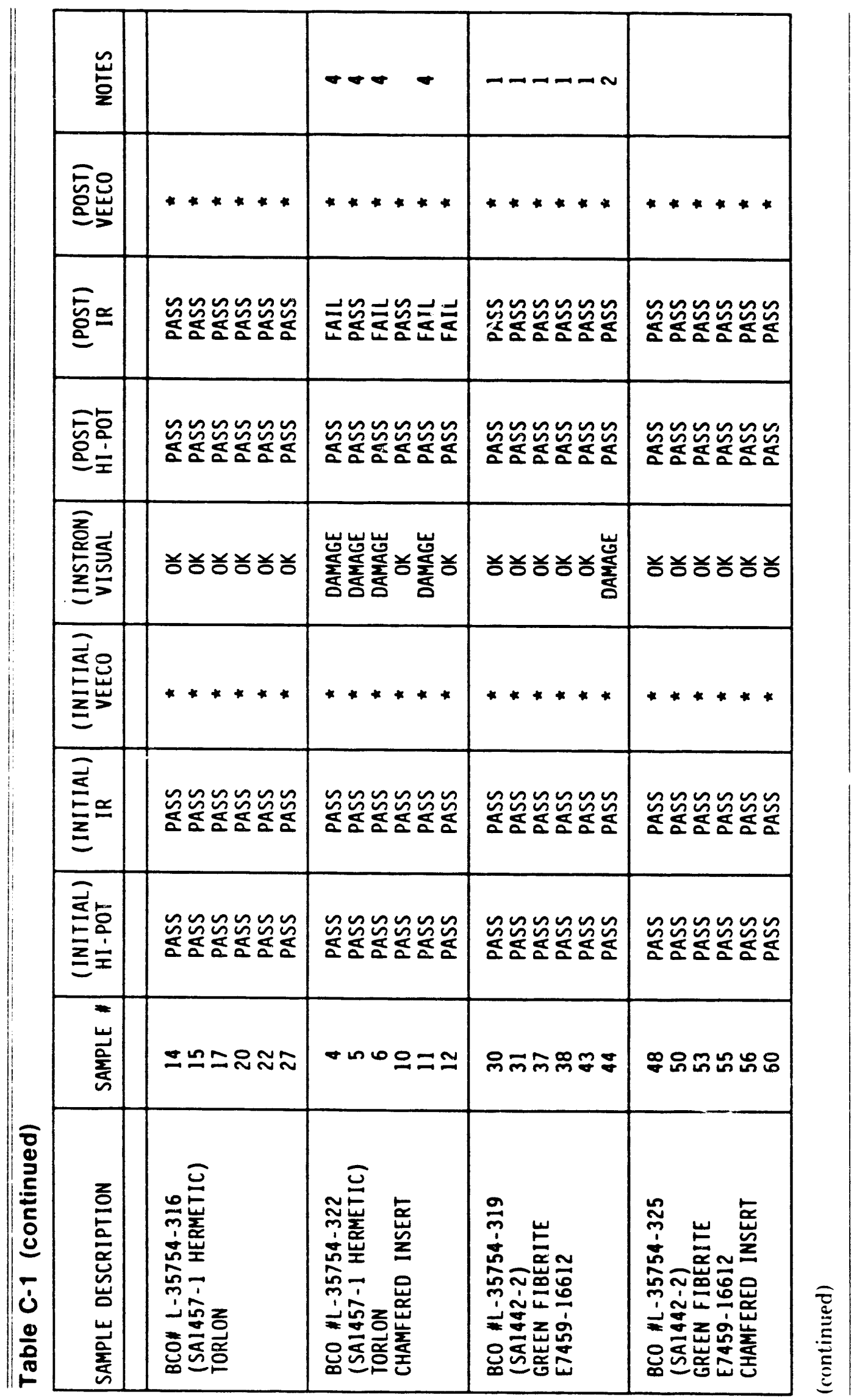




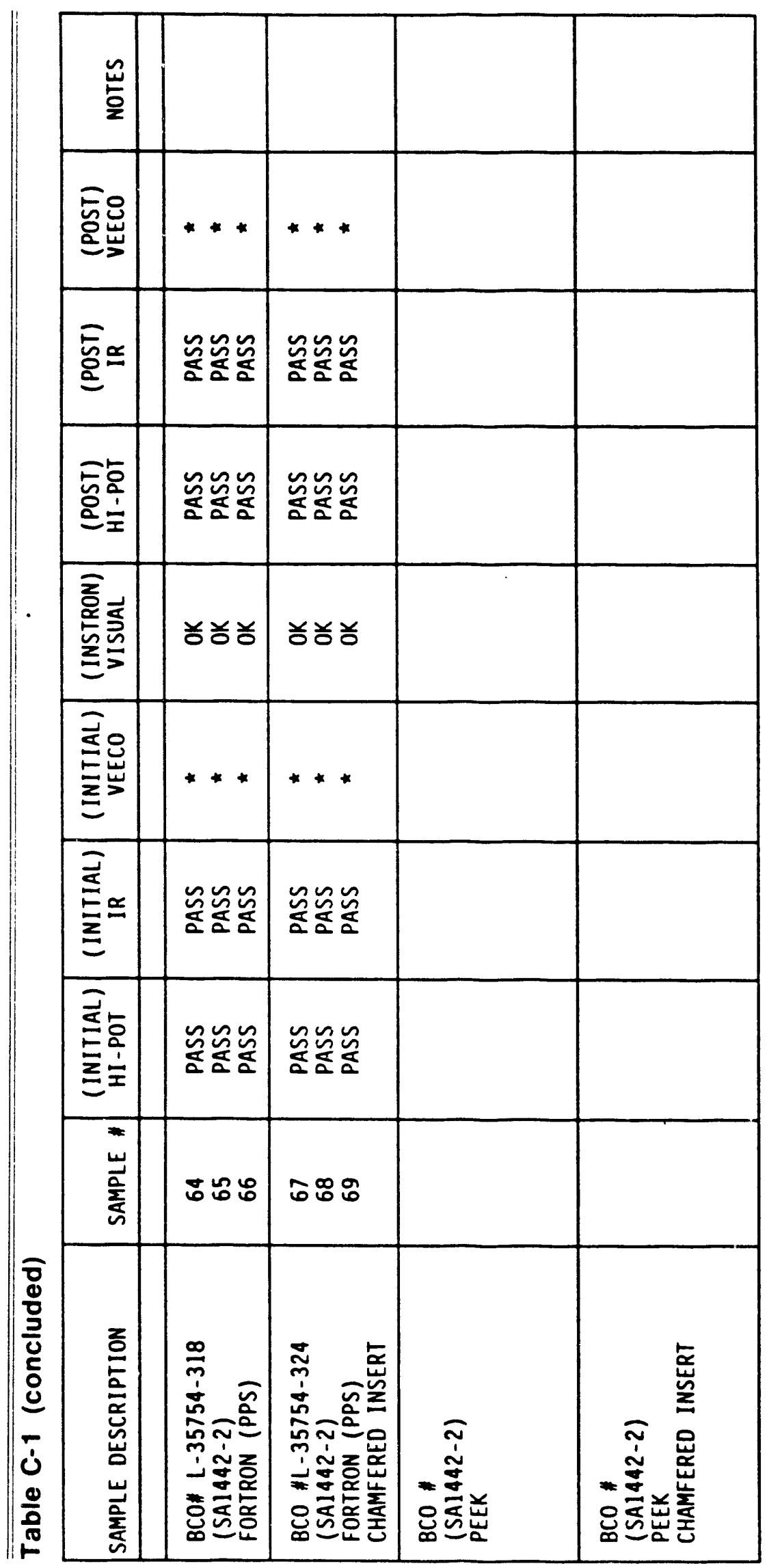

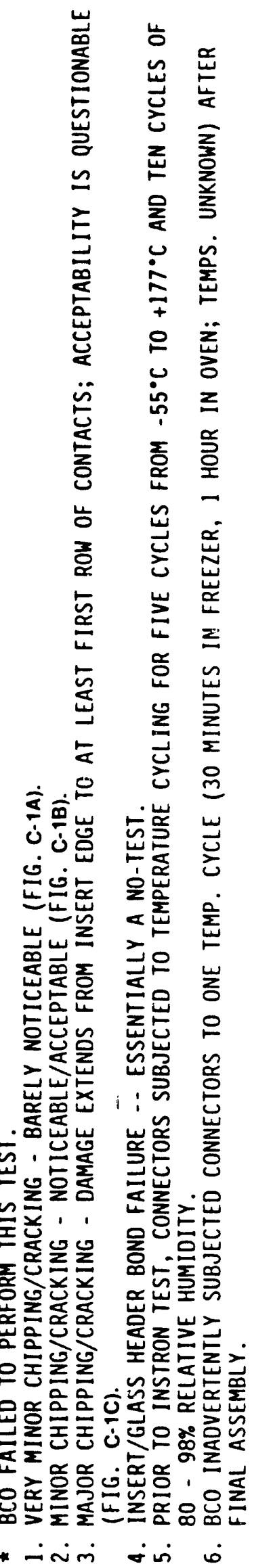




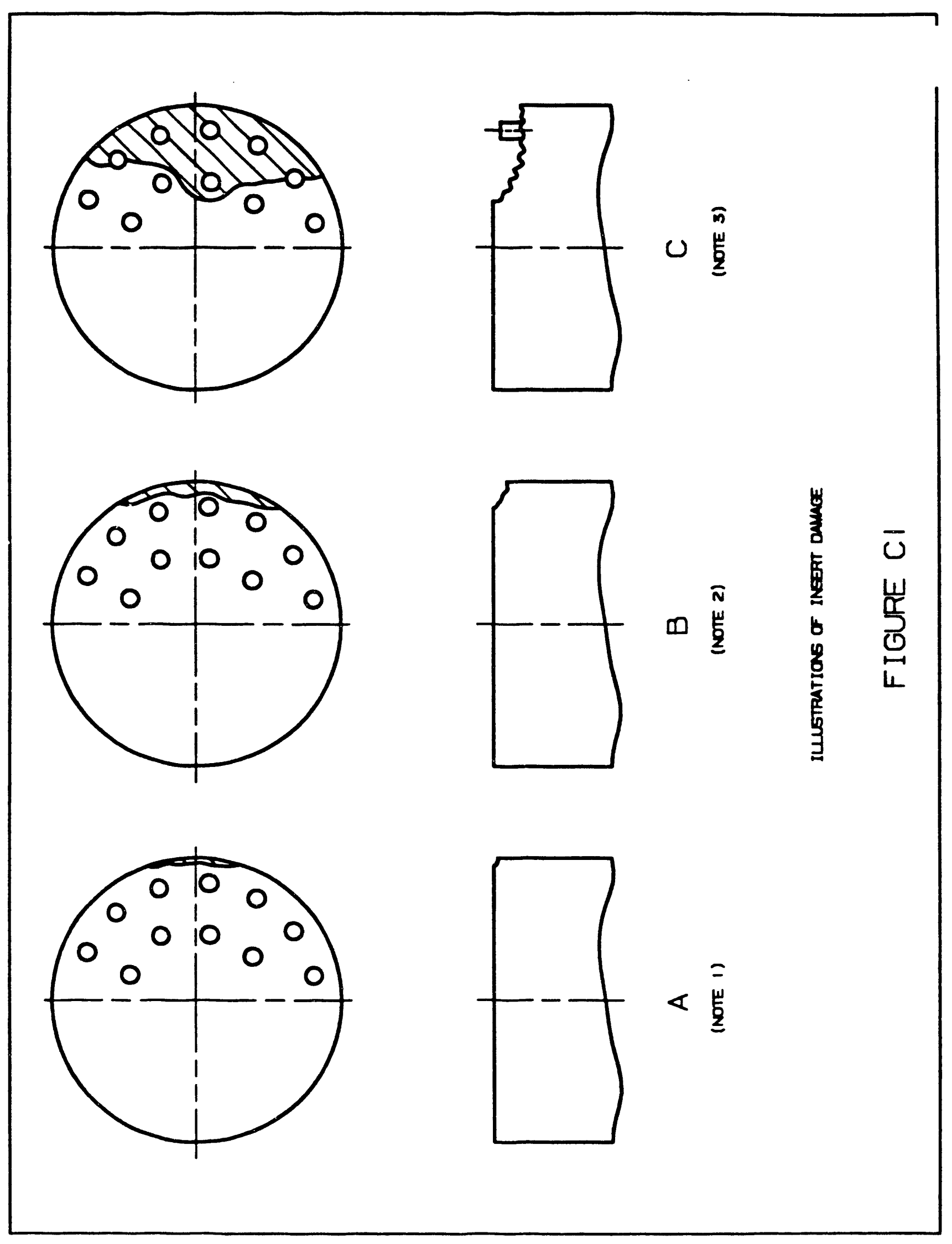




\section{APPENDIX D}

Results of Cable Pull Test 


\section{Summary}

Command and Control Division I (5126) performed two sets of cable pull tests, replicating fielduse conditions. Each set of pull tests consisted of pulls made in four directions approximately $90^{\circ}$ apart (Figure D-1). One set is performed by pulling at the potting boot (3-in. lever arm) and the other set at the cable itself (12 to $18 \mathrm{in}$. lever arm). The connector samples were mounted in a T1533 decoder at the J3 position. Army CT1503 PAL cables were used to perform the cable pull tests. Each connector sample was subjected to the two sets of cable pull tests above. Each pull test was a sideways disconnect pulling/ yanking action, preceded by a complete mating of the connector pair, followed by disengagement of the coupling ring without separating the mated connector bodies.

The initial plan was to Instron-test four and pull-test four of each type of connector sample after subjecting them to temperature cycling and humidity tests intended to replicate field environments. The frequency of the insert-to-glass header bond failures in hermetic connectors after simulated environments prompted the discontinuance of simulated environmental exposure and subsequent cable pull testing on the remaining (Torlon, Fiberite E264H) connector samples.

The level of insert damage sustained for each connector is recorded in Table D-1.

\section{Results}

Damage results ranged from no chipping to major chipping. These tests also demonstrated that the $30^{\circ}$ bevel on the insert outer edge reduces the amount of edge chipping that occurs. The cable pull tests show that the bevel provides a $75 \%$ reduction in chipping compared to regular connector inserts with no bevel edge. The hermetic connectors proved inadequate as test samples because the insert-to-glass header bond broke loose curing cable pull tests. Visual damage assessment was made with both the naked eye and under $7 \times$ magnification.

\section{Conclusions}

Connectors with thermoplastic inserts exhibited no damage, whereas those with Fiberite (thermoset) inserts experipnced some degree of damage in most cases. The best performing insert material was Fortron, a thermoplastic.

Although it is difficult to predict the reason damage occurred on some of the connectors, I believe that both impact and interference-induced stress were factors. After witnessing the test, jiggling the connector to free it, then whipping it loose, I suspect that damage was being caused by the connector's shell impacting the insert-in some cases at the point of interference and in other cases at a point opposite. 


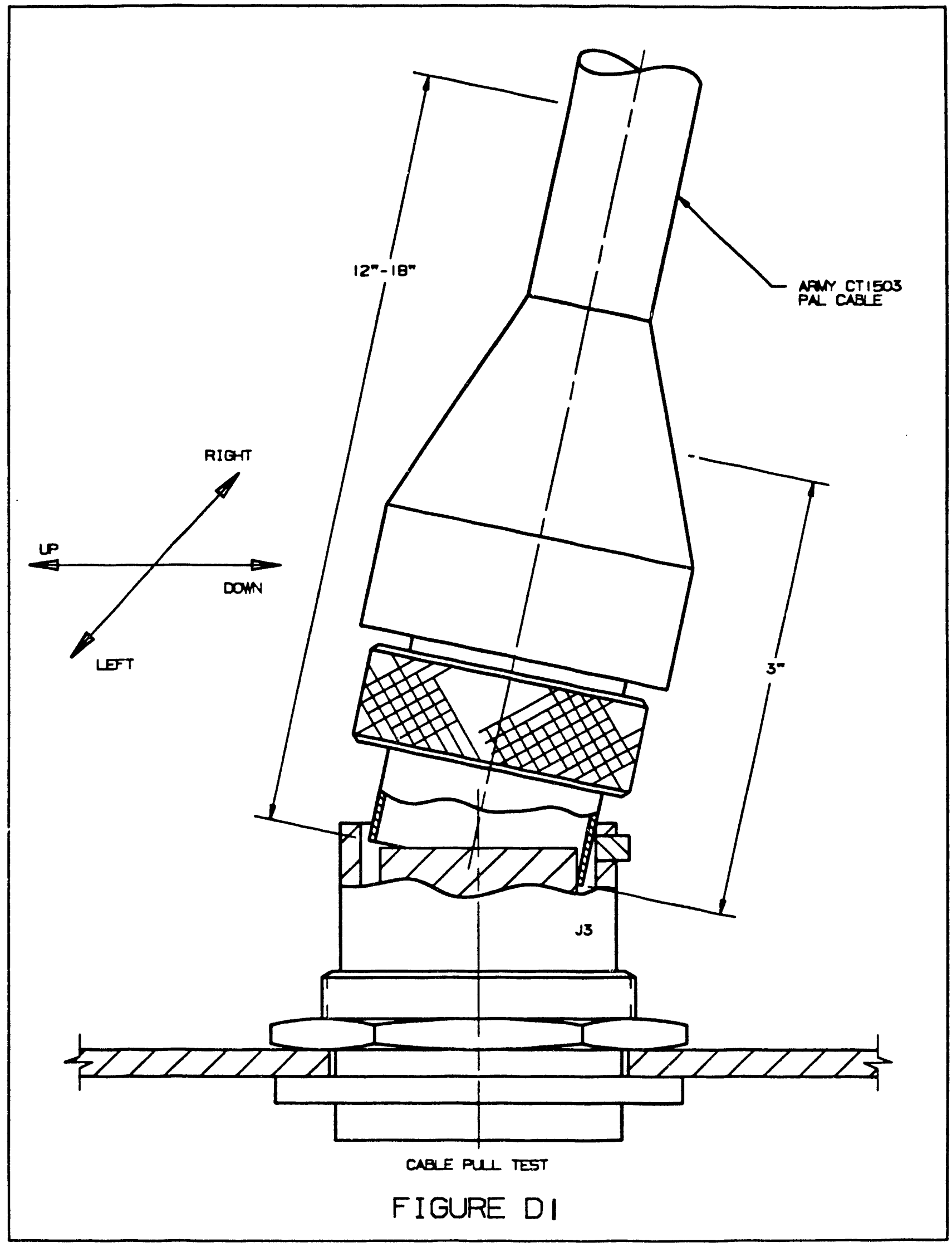




\begin{tabular}{|c|c|c|c|c|c|c|}
\hline 岕 & 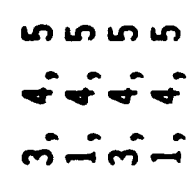 & 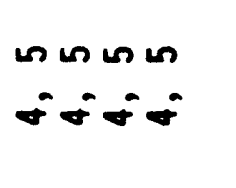 & 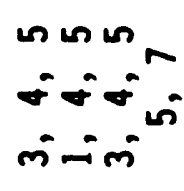 & 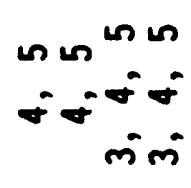 & 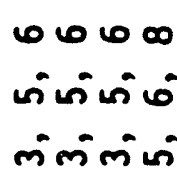 & 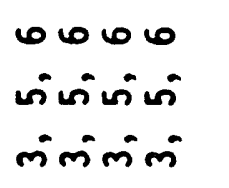 \\
\hline 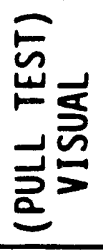 & 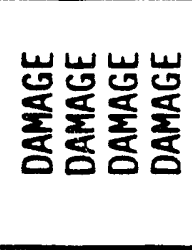 & 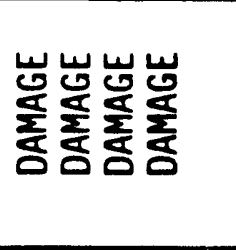 & 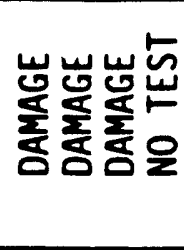 & 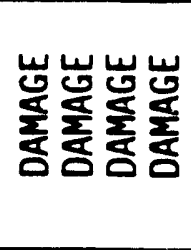 & 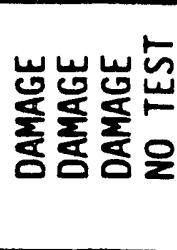 & 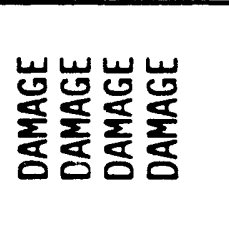 \\
\hline $\begin{array}{l}\text { ఏ。 } \\
\text { 巨出 } \\
\text { 至 }\end{array}$ & 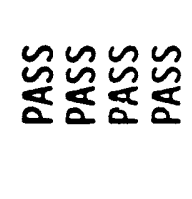 & 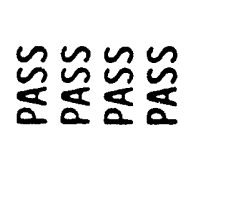 & 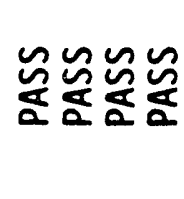 & 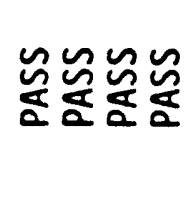 & 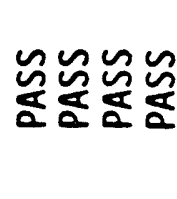 & 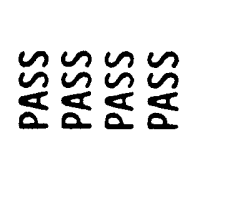 \\
\hline $\begin{array}{l}\text { ఏ } \\
\stackrel{\Xi}{\Xi} \cong \\
\Xi\end{array}$ & 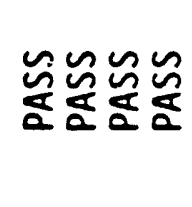 & 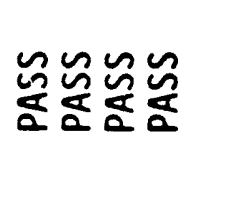 & 气ุ气ñ & 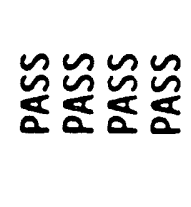 & 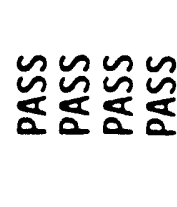 & 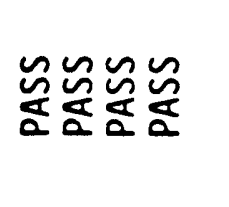 \\
\hline 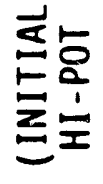 & 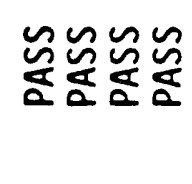 & 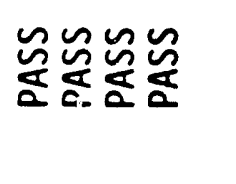 & 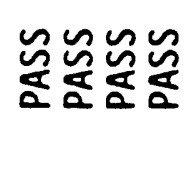 & 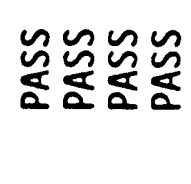 & 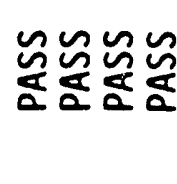 & 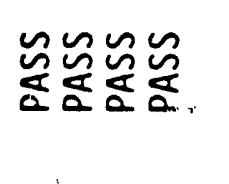 \\
\hline $\begin{array}{l}w \\
\frac{a}{\frac{\alpha}{z}} \\
\frac{\alpha}{\alpha}\end{array}$ & $-c$ & 표요 & $-\infty$ & $\vec{\sim} \approx \tilde{N}$ & 으므든 & 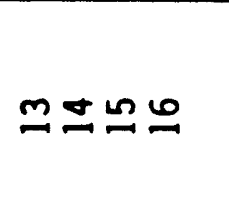 \\
\hline 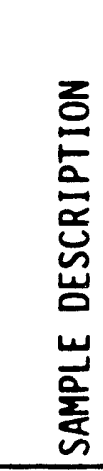 & 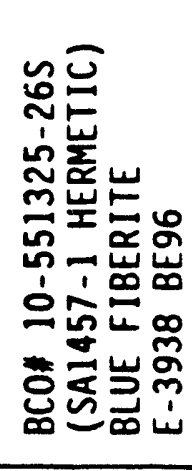 & 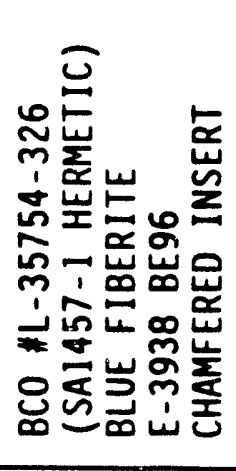 & 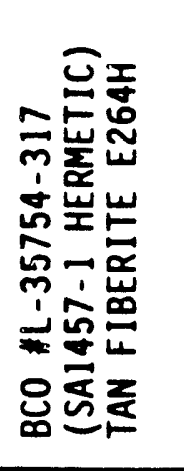 & 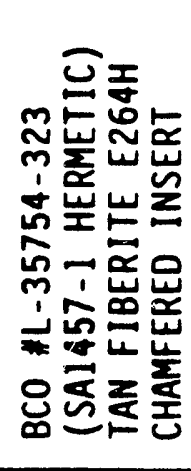 & 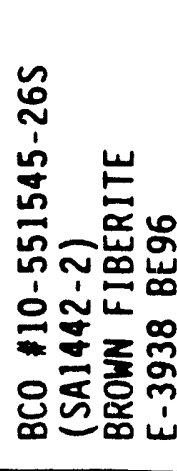 & 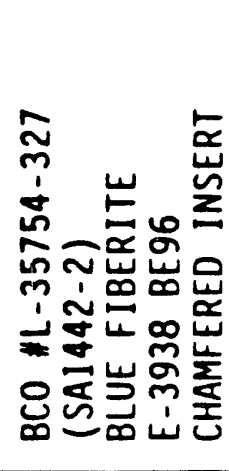 \\
\hline
\end{tabular}

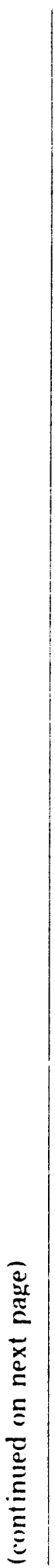




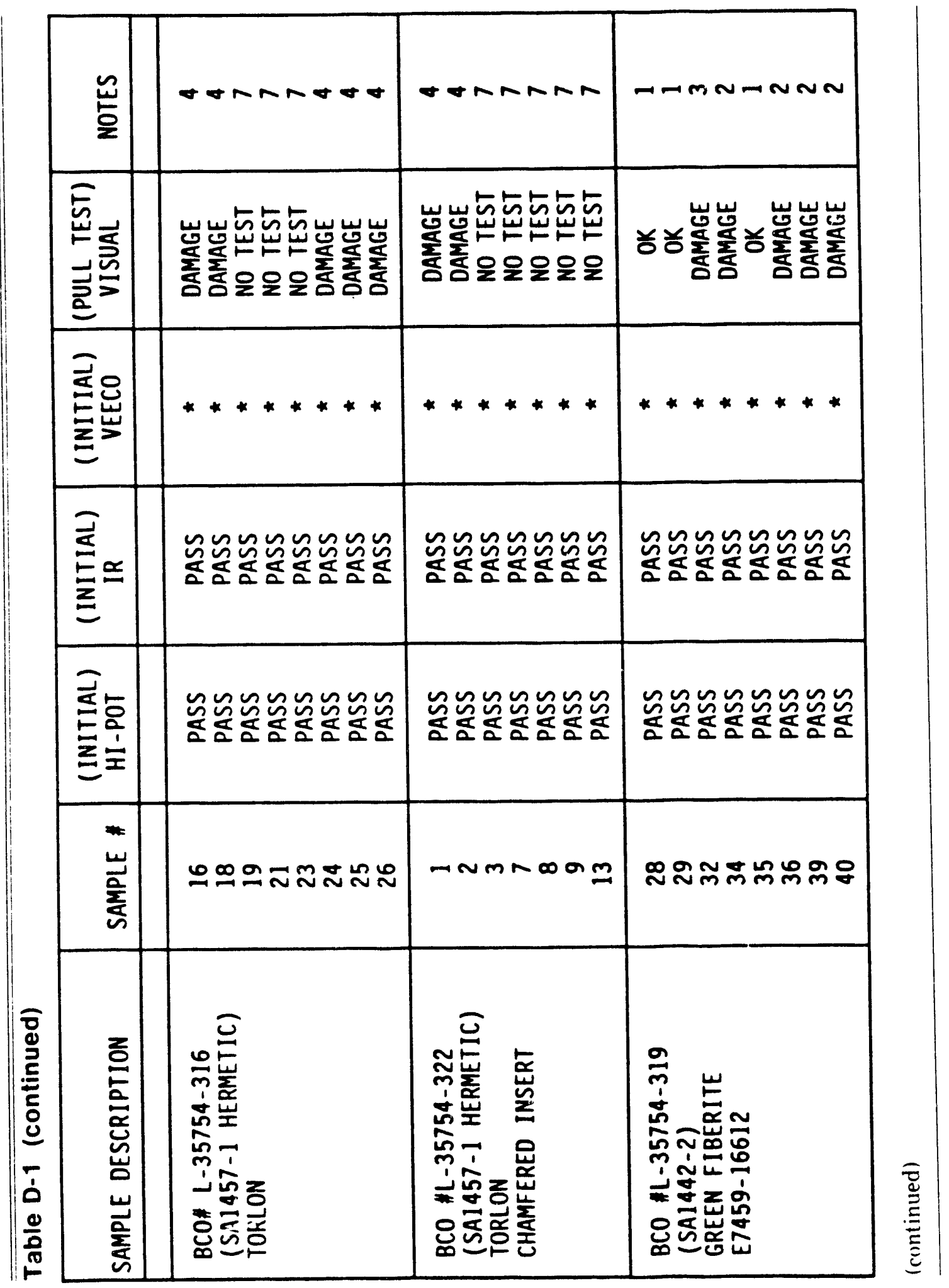




\begin{tabular}{|c|c|c|c|}
\hline$\underset{5}{\stackrel{5}{5}}$ & $m \quad-7$ & & \\
\hline 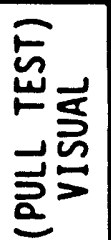 & 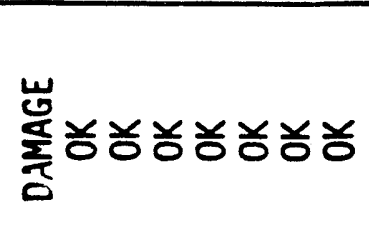 & 危并并 & 石并㒸 \\
\hline 至号 & $* * * * * * * *$ & $* * *$ & $* * *$ \\
\hline$\underset{\underline{\Xi}}{\stackrel{\Xi}{\Xi}}$ & 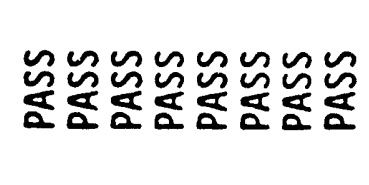 & 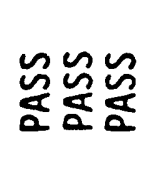 & 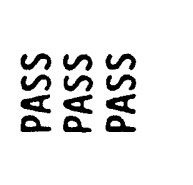 \\
\hline 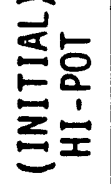 & 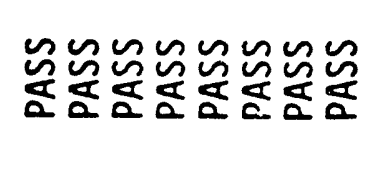 & 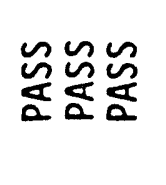 & 气ू̆ \\
\hline 宸 & 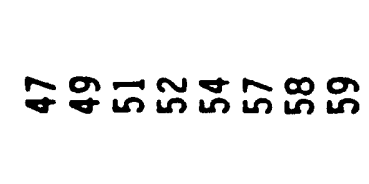 & ธธีอ & RニN \\
\hline 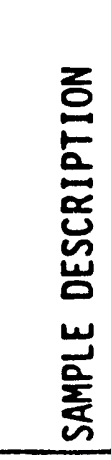 & 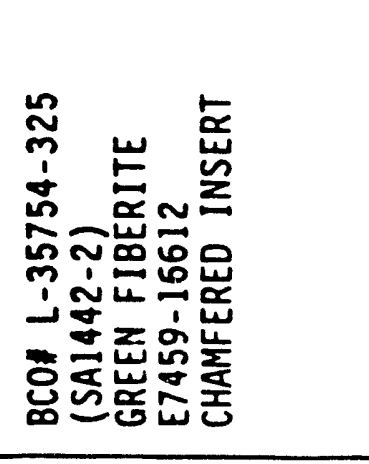 & 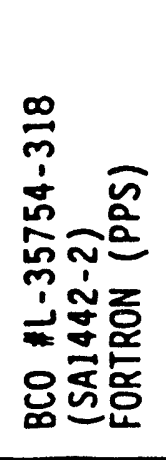 & 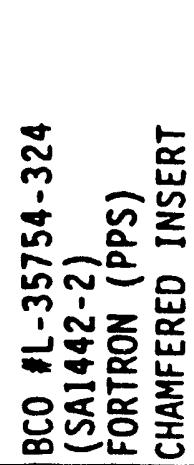 \\
\hline
\end{tabular}

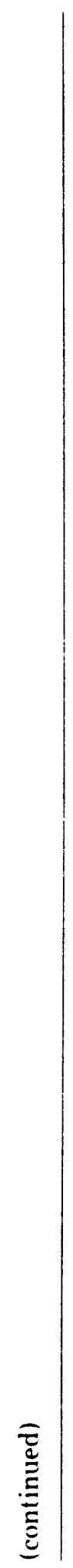



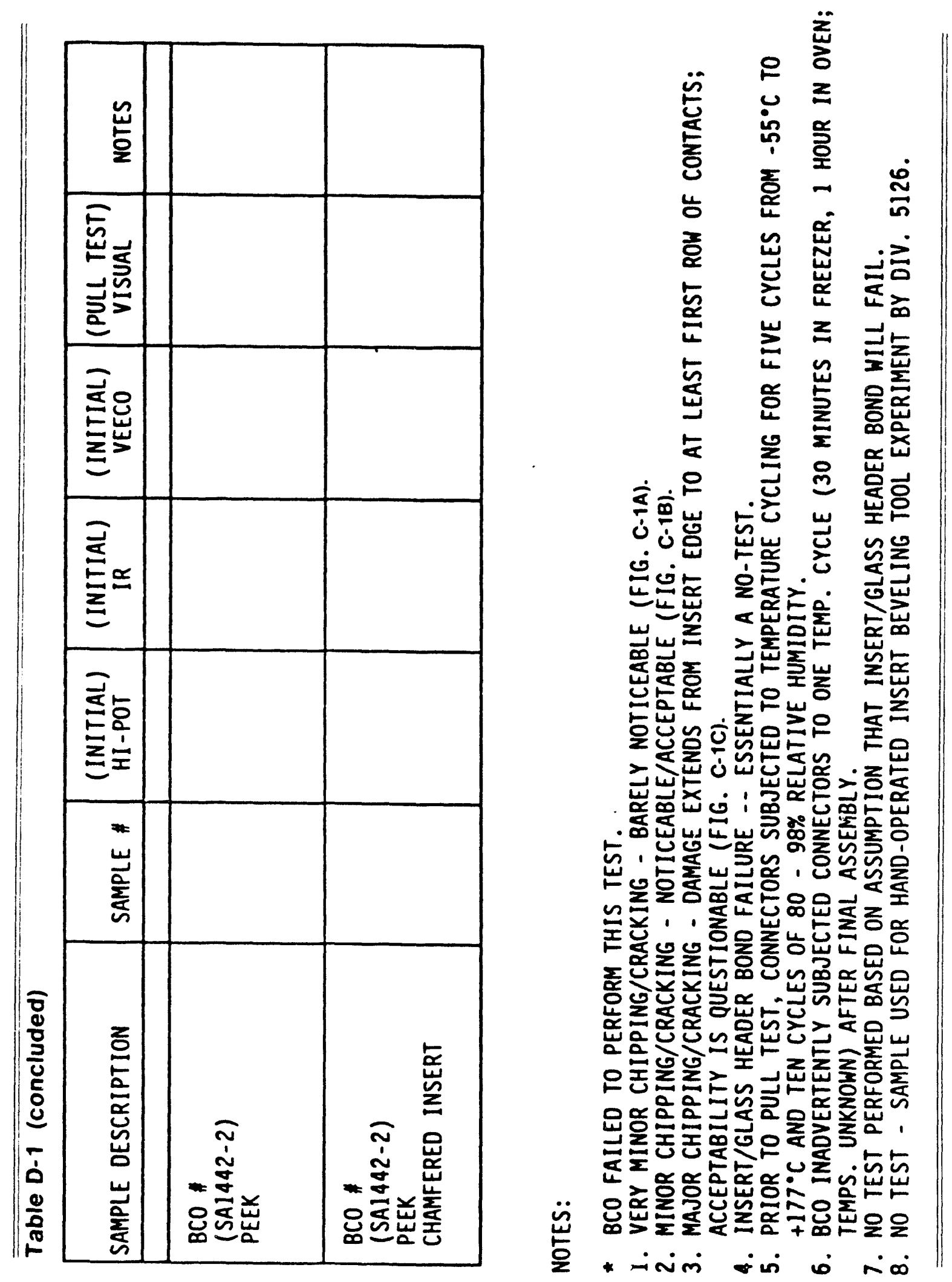


\section{APPENDIX E}

Results of Insert Test 


\section{Summary}

Hermetic connector inserts have a history of breaking along the edges and across the contact aligning web (Figure E-1A, B). The objective was to compare the strength of six materials in the contact aligning web area. Two holes were punched out in each insert (Figure E-2A), one approximately in the center of the insert and one along the perimeter (Figure E-2C). The test was to be run at moderate speed (i.e., distinct from an impact test or a tensile test). The test was performed on the Instron using a speed of $20 \mathrm{~mm} / \mathrm{s}$ nominal.

Three of six inserts for each material in both configurations (Figure E-2B) were subjected to temperature cycling for five cycles from $-55^{\circ} \mathrm{C}$ to $+177^{\circ} \mathrm{C}$ and ten cycles at $80 \%$ to $98 \%$ relative humidity.

\section{Results}

Test results summarized in Table E-1 show the forces required to punch out the contact aligning web. Materials exhibiting the greatest change due to temperature cycling and humidity were Torlon and Fiberite E264H. Fiberite E264H and E-7459-16612 exhibited equal strength after simulated environmental exposure. Fortron exhibited the greatest strength overall. With the exception of Fiberite E-3938 BE96, all the materials fractured and failed but held together with their filler materials. E-3938 BE96 fractured, failed, and fell off completely. PEEK inserts have not been received yet; hence, we have no test results.

BCO discourages using Torlon and Fiberite ¿264H. The stainless-steel core pins used to create the contact cavities exhibited wear due to the high pressures required to mold these two materials. 


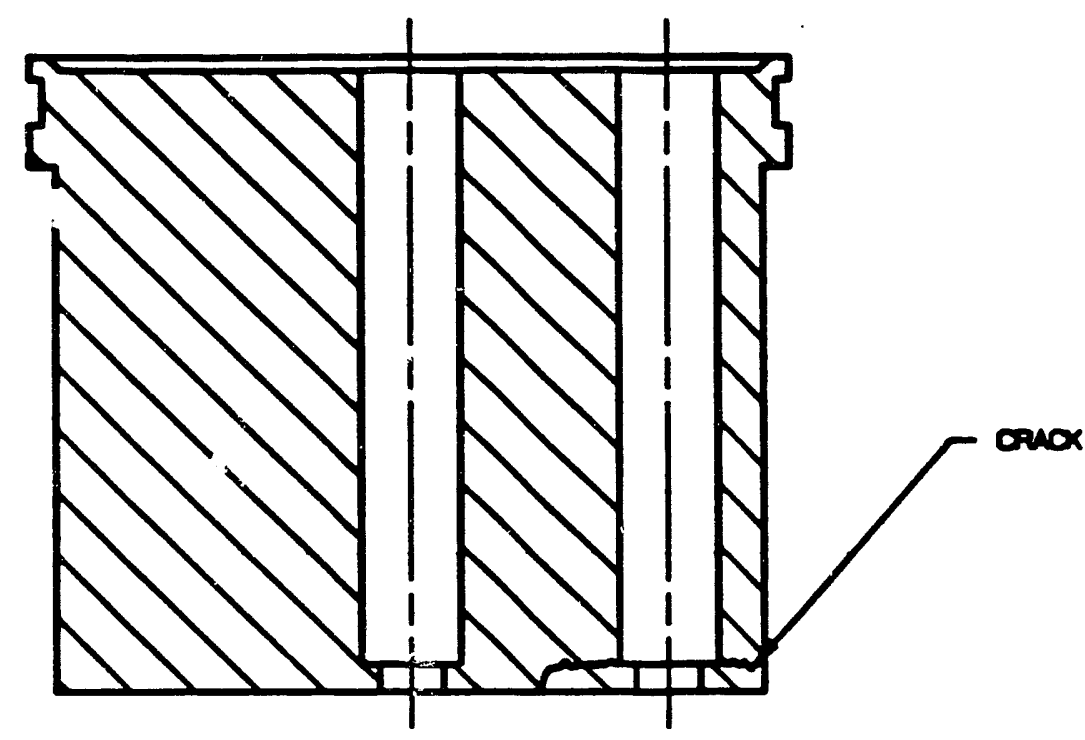

A

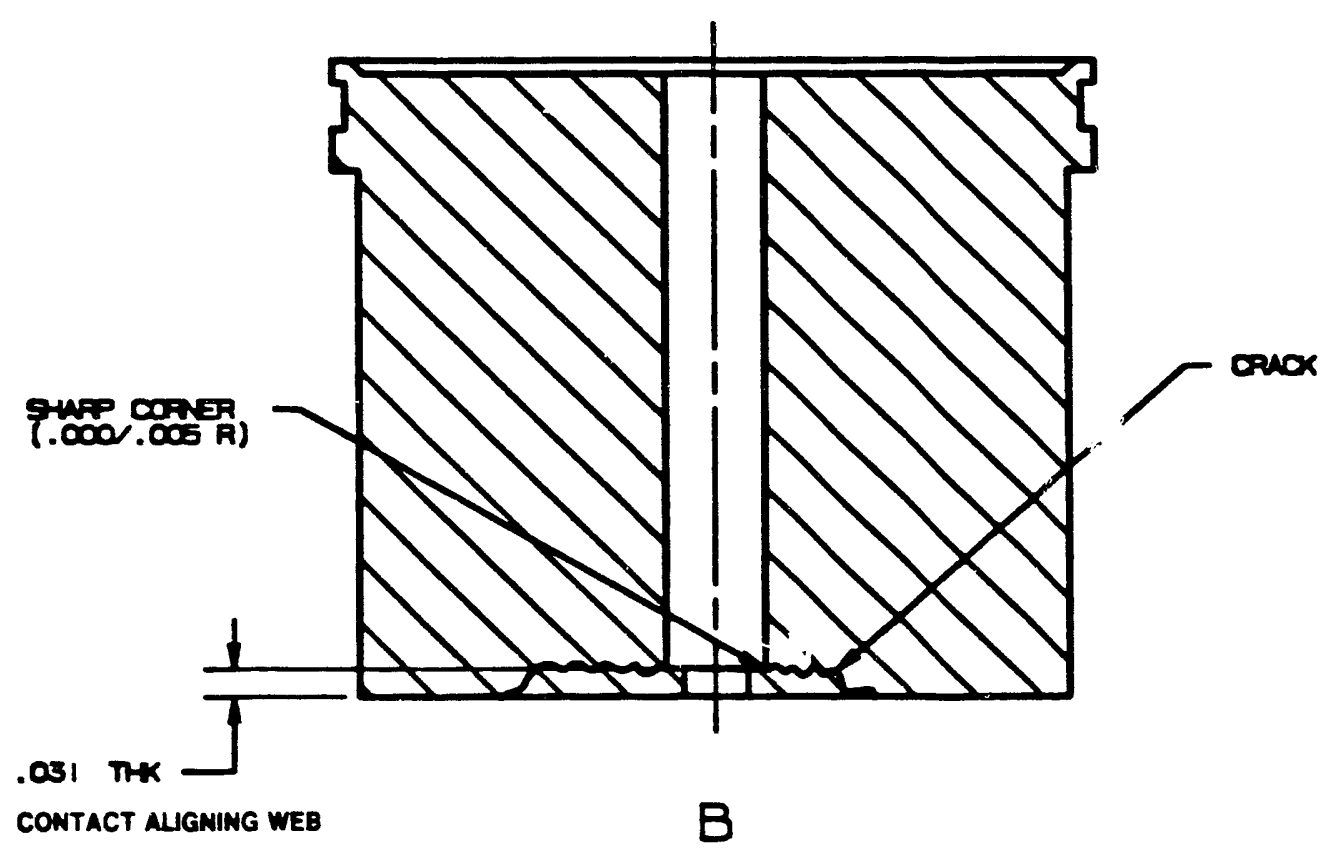

IUUSTRATIONS of DEAKACE

FIGURE EI 


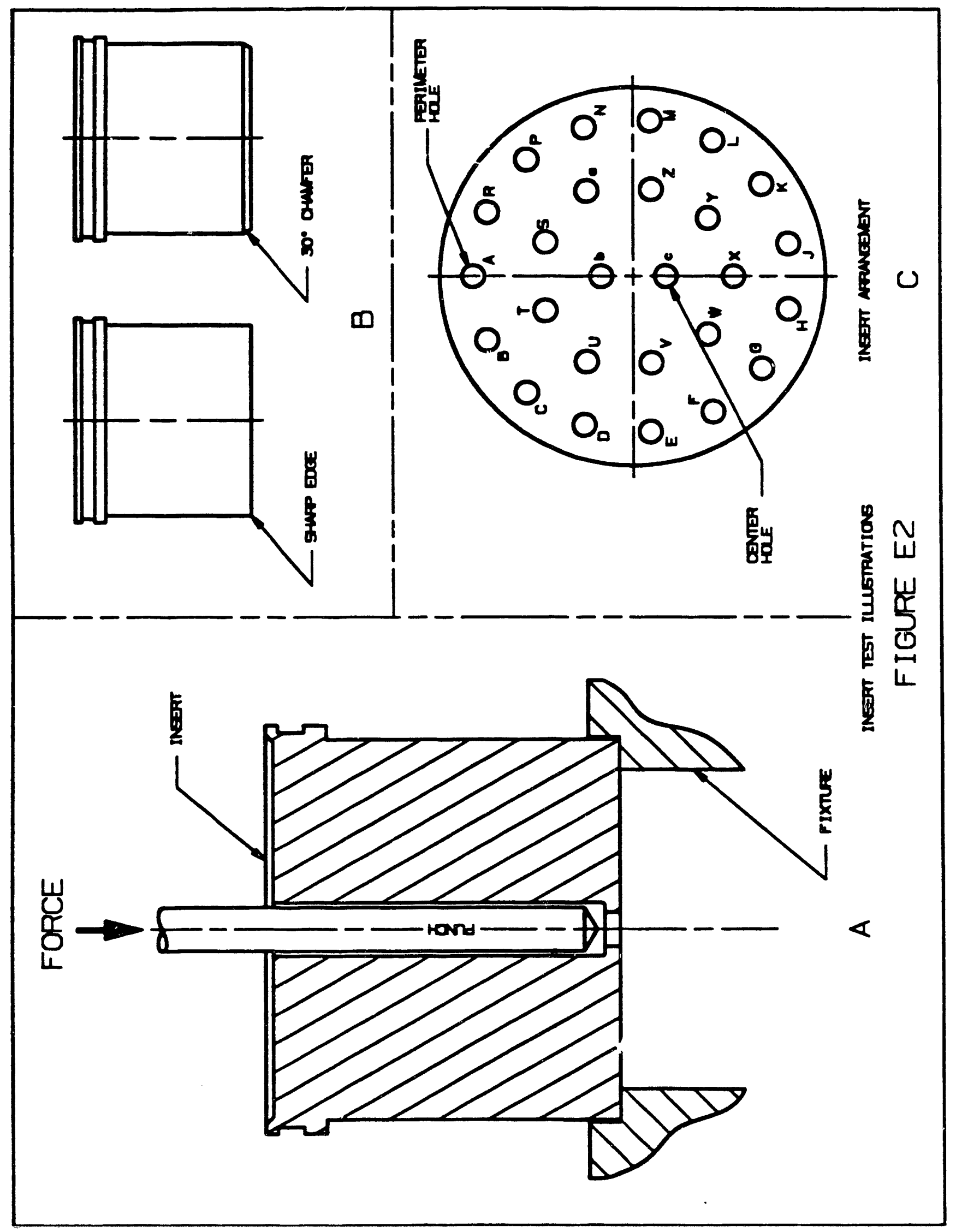




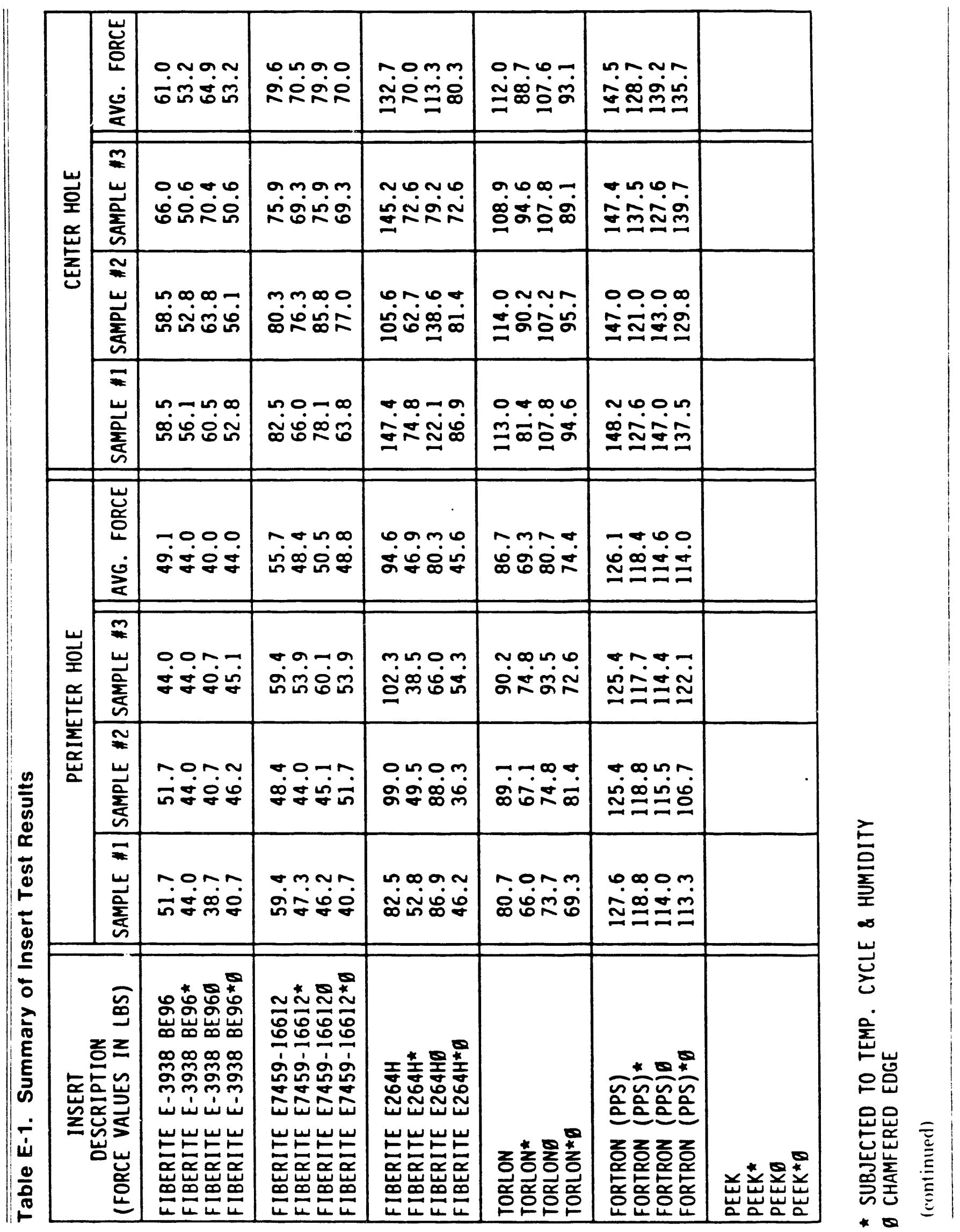




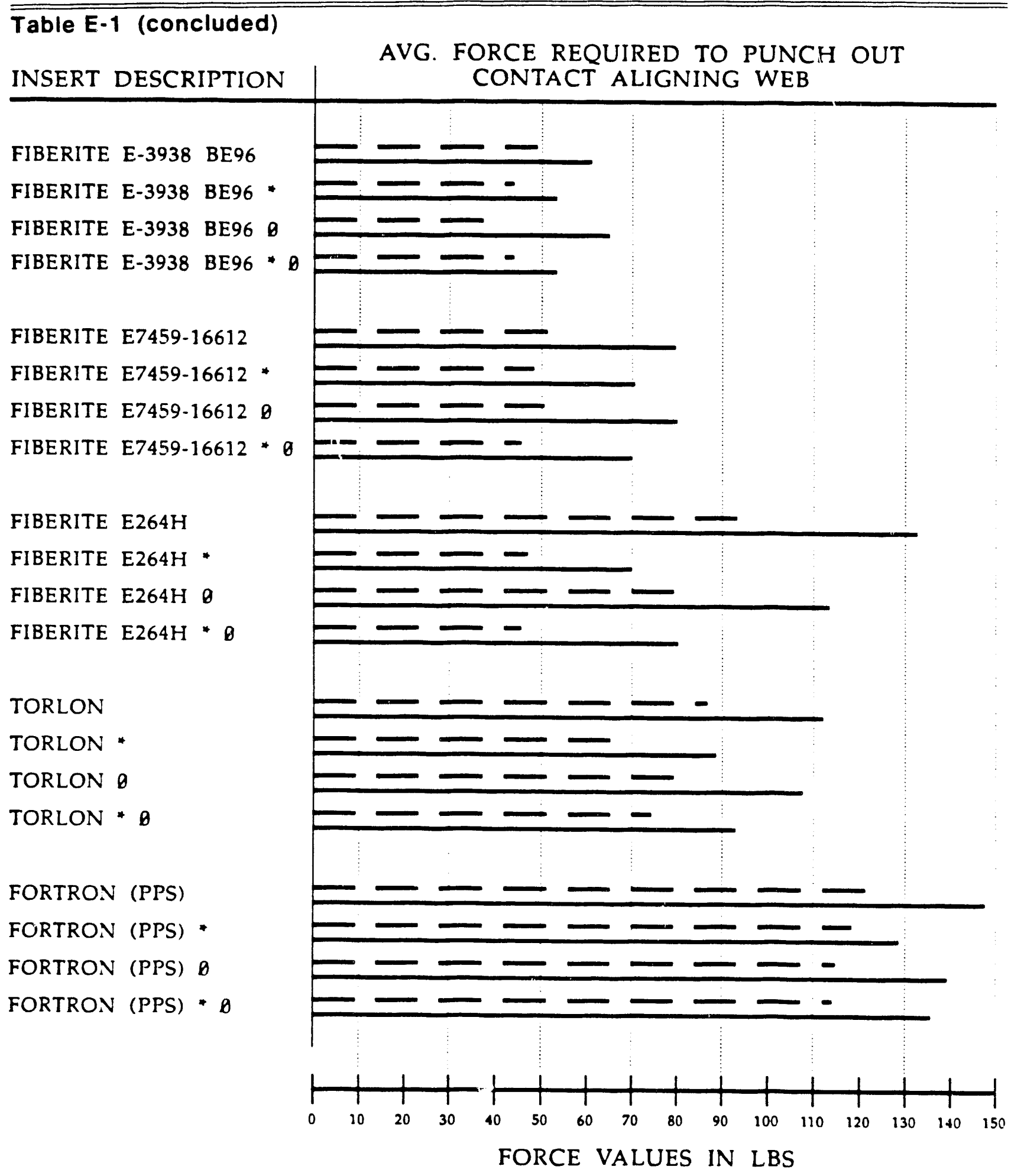

LEGEND:

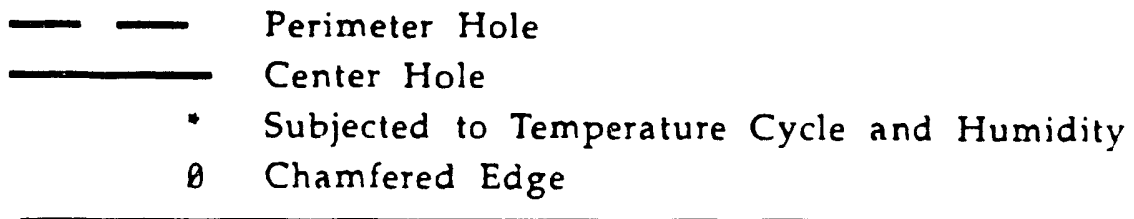




\section{APPENDIX F}

\section{Insert Tolerance Studies}




\section{Summary}

As noted earlier in the Instron and Pull Test results, the simplest way to relieve any interference in the insert edge area is to chamfer or "radius" the edge itself. For experimentation purposes, the 17-26 insert arrangement was selected to serve as the benchmark since the most co nmon connector size experiencing insert damage was the 17 -shell size. The chamfer size selected was BCO's recommendation (Figure F-1A).

Test results show a definite improvement by chamfering the insert edge; however, thinning down the wall at the upper end of the contact guide hole proved to be undesirable (Figure F-1A). In addition, the chamfer used in the test experiments cannot always be used for other insert arrangements.

A tolerance study was performed for all JT/LJT insert arrangements applicable to "SA" and " $\mathrm{MC}$ " connectors. The insert arrangement most vulnerable to chamfering is $15-18$. In order to provide a "comfortablen 0.010 in. of material from the edge of the contact guide hole to the chamfer edge, a maximum chamfer angle $c ? 14^{\circ}$ is required (Figure F-1B).

A comparison of the worst-case conditions for insert arrangements 17-26 and 15-18 can be found in Figure F-1, A and B.

Without further testing, I speculate that a $14^{\circ}$ chamfer would provide limited improvement and would not be cost-effective.

\section{Conclusion}

Based on this study, I believe a superior insert material is required to optimize chipping resistance without altering the connector design. 


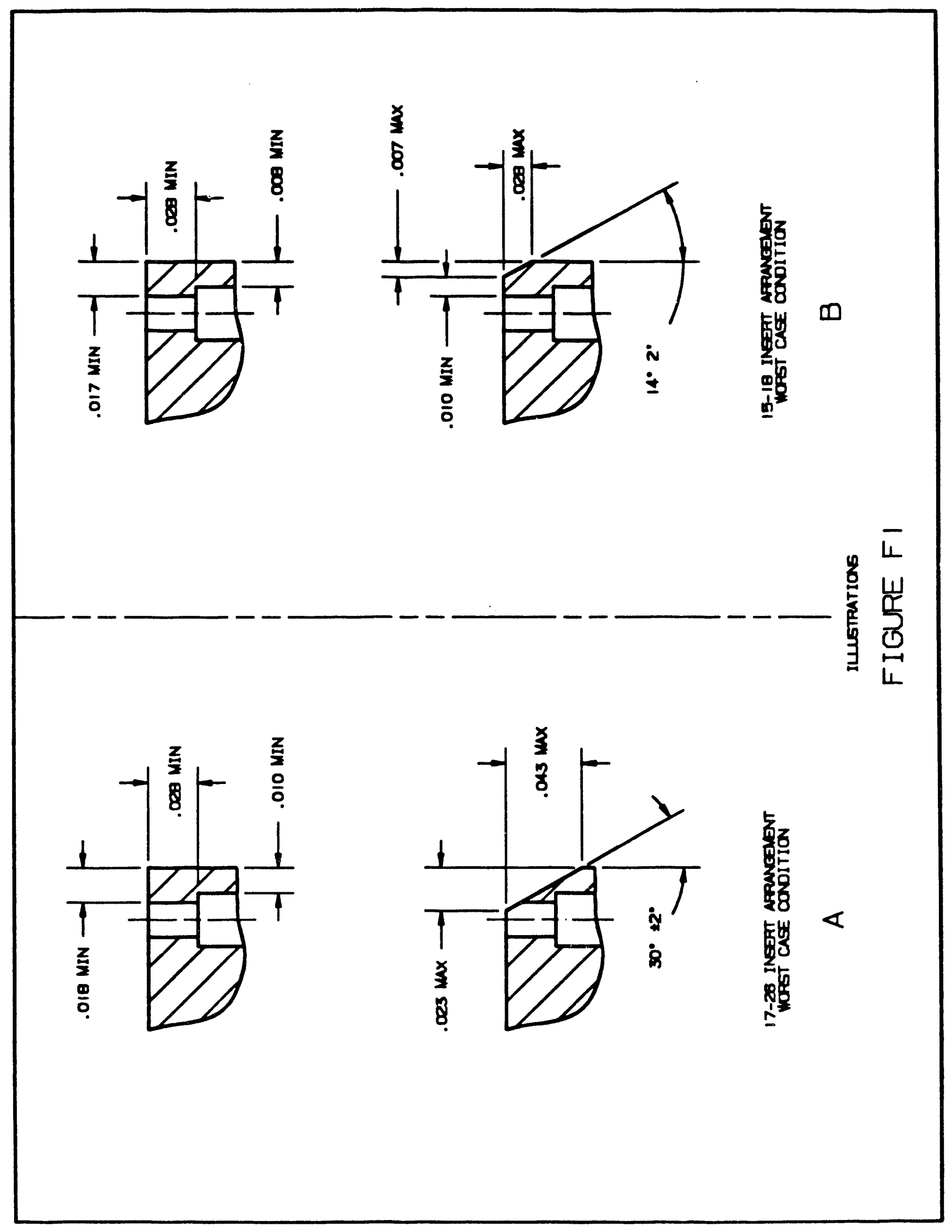




\section{Summary}

The reconfigurated insert and metal shell-edge geometries were evaluated for the purpose of reducing the alleged interference deemed primarily responsible for insert damage.

Numerous reconfiguration combinations were tried graphically but none showed promise in eliminating the problem. The primary configurations are illustrated in Figure G-1.

The studies showed that, at the point of disengagement when insert chipping occurs, the principal areas of interference are between the bayonet pins and the coupling ring and/or the receptacles' shell and the coupling ring. However, a small amount of interference exists between the insert and plug shell.

Reconfiguration of the insert and metal shell. edge geometries would provide interference relief but would not eliminate the insert chipping problem. As mentioned earlier in the Connector Test results, chip- ping appears to be caused by impact rather than by interference-induced stress.

The cost to reconfigure the metal shells and inserts may not be justifiable, considering the magnitude of the interference.

\section{Test Results}

Six SA1442-2 connectors with approximately $30^{\circ}$ chamfers on the insert and shell (Figure G-2) were subjected to cable pull tests (Figure D-1). No improvement in chipping resistance was evident, lending credence to the hypothesis that chipping is principally caused by impact.

\section{Conclusion}

Based on this study, I believe that a superior insert material is required to optimize chipping resistance without altering the connector design. 
APPENDIX G

Configuration Studies and Tests 


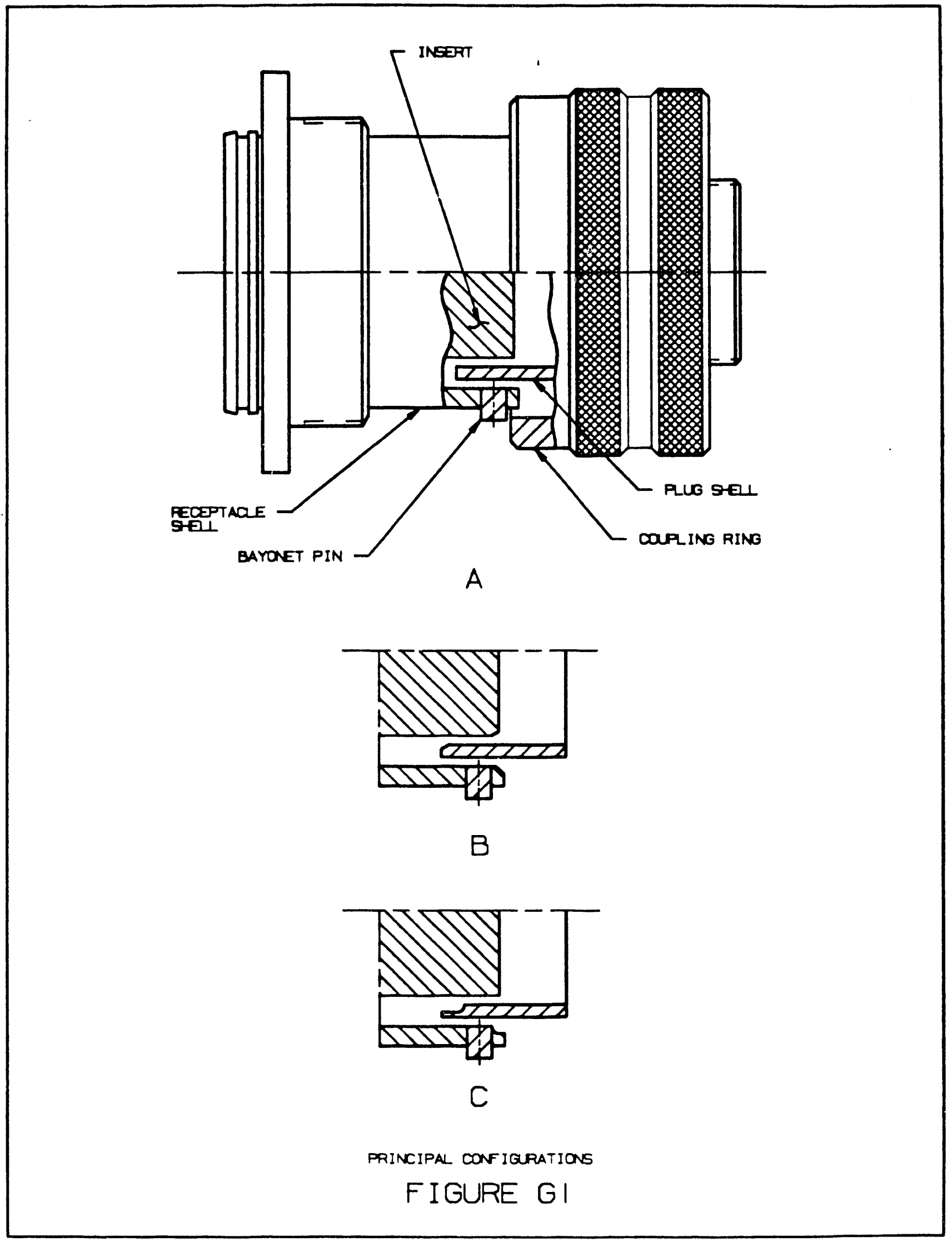




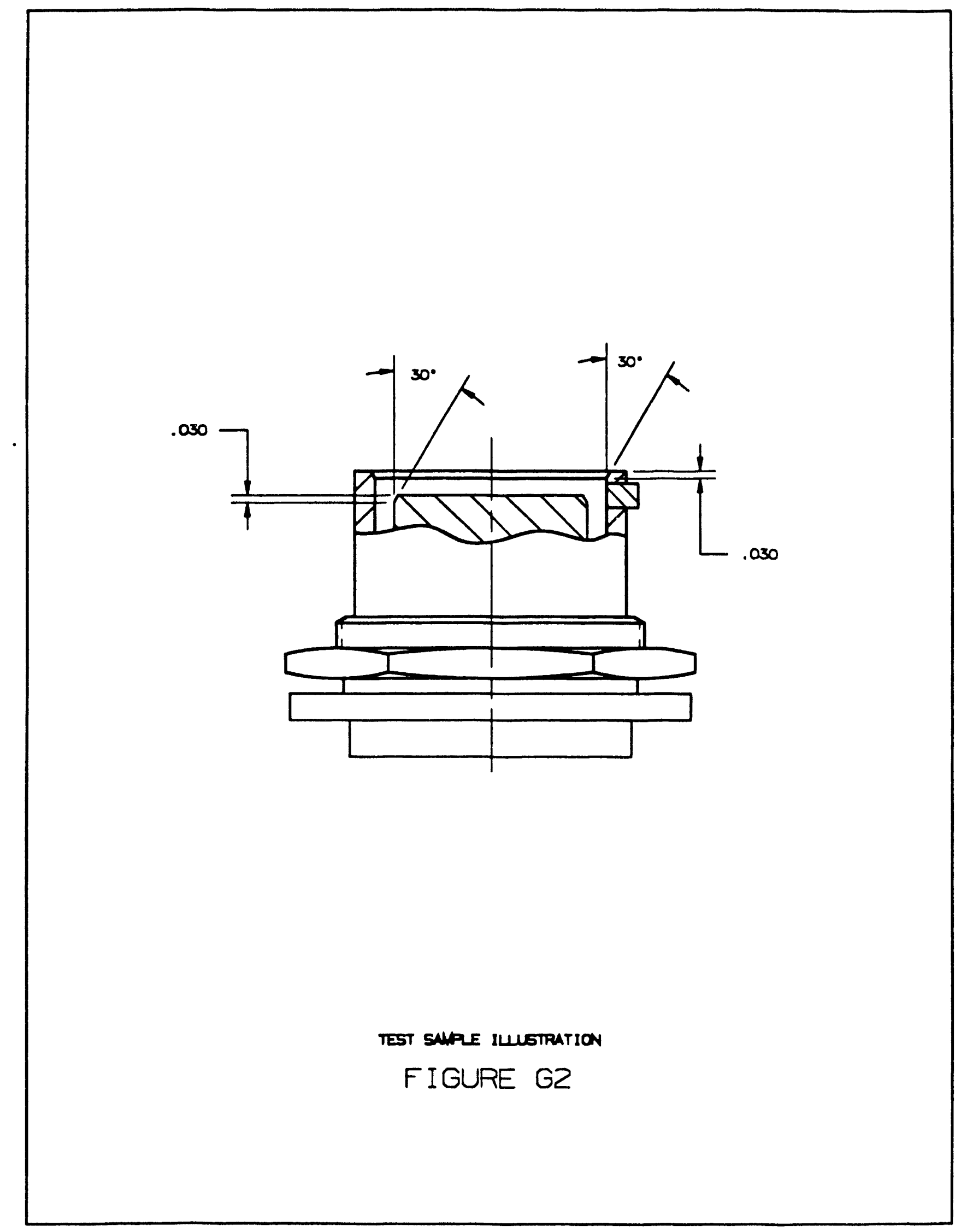




\section{APPENDIX H}

\section{Support Request Memo to the Organic Materials Division}

(without attachments) 


\section{Sandia National Laboratories}

dale: March 12, 1991

Albuquerque. New Mexico 87185

10. K. B. Wischmann, 7472

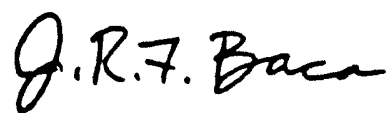

from. J. R. F. Baca, 2551

subject: Connector Insert Material Evaluation

This memo requests your support in selecting/recommending an insert material which will exhibit substantially improved resistance to damage such as chipping, cracking, etc. The material must continue to be able to meet all other requirements currently in effect.

The material presently used is Fiberite E3938, a thermoset plastic consisting of $30 \%$ epoxy resin and $70 \%$ one-eighth inch long glass fibers.

The candidate materials being evaluated by Division 2551 are:

1. Fiberite E7459-16612: a thermoset plastic consisting of $60 \%$ epoxy resin and $40 \%$ one-fourth inch long glass fibers.

2. Fiberite E264H: a thermoplastic consisting of $40 \%$ epoxy resin and $60 \%$ onefourth inch long glass fibers.

3. Torlon 4203L (Amoco Chemical Co.): a polyamide-imide molding compound; unreinforced thermoplastic.

4. Eortron 1140L4 (Hoechst Celanese): a polyphenylene sulfide, $40 \%$ fiber glass, low flash grade thermoplastic.

5. PEEK RTP2205 (RTP Co.): a polyetheretherketone, 30\% fiber glass reinforced thermoplastic.

Both, Fiberite E264H and Torlon 4203L require very high molding pressures, and therefore, can only be used to mold hermetic connector inserts. However, both materials exhibited abrasive wear during molding, so their use is highly discouraged by the connector manufacturer.

At my request, Fiberite Corporation recommended four thermoset materials, two in particular.

1. Eiberite E8354-19189: a thermoset plastic having a resin matrix much more resistant to chipping than the thermoset materials listed above. 
2. Eiberite TEM 9001: a thermoset plastic having a toughened epoxy resin and glass/mineral reinforcement.

3. Fiberite TEM 9010: a thermoset plastic having a toughened epoxy resin and glass/mineral reinforcement.

4. Fiberite TEM 9025: a thermoset plastic having a toughened epoxy resin and one-half inch long (one-fourth inch available) E-glass reinforcement.

Fiberite Corporation's primary recommendations are Fiberite E8354-19189 and TEM 9001 . The principal difference being greater chip resistance in TEM 9001 due to toughened epoxy resin.

Except for TEM 9025 these are granular products. Molding methods and processes are virtually identical to Fiberite E3938, E7459-16612, and E264H.

Fiberite highly recommends using one of these four materials in place of E3938, E745916612 , and $E 264 \mathrm{H}$ which is 20 year old technology and has very poor batch quality control.

Product data sheets are attached for your review.

Your costs should be budgeted and charged to case number 0034.200 .

JRFB:2551:ve

Copy to:

2550 D. W. Doak

2551 D. E. Carnicom

2551 M. J. Craig

7472 J. A. Sayre

2551 J. R. F. Baca

2551 Dayfile (w/o attch.) 


\section{APPENDIX I}

\section{Memo to BCO Requesting}

Time and Cost Estimates 
Albuquerque. New Mexico 87185

February 4, 1991

Amphenol Corporation

Bendix Connector Operations

40-60 Delaware Street

Sidney, NY 13838-1395

ATTN: J. B. Becker

Dear Joe:

Subject Time and Cost Estimate for Molding New JT/LJT Insert Material

Please provide time and cost estimates for molding PEEK, FORTRON (PPS), and Fiberite E16612 inserts for SA 1442-2 and SA1457-1 connectors. These two connector types will serve as benchmarks for evaluation purposes.

As per our January 24 telecon, I am requesting that you provide time and cost estimates for each of the following:

1. FIBERITE E16612.

- Material shrinkage study

- Transfer molds that provide a beveled edge (fig. 1B)

- Tapered core pins (fig. 1B)

- Establish the molding process

- Time required to become ílly operational

- Cost per connector (SA 1442-2 and SA 1457-1) in quantities of 100 or more

2. FORTRON (PPS) $1140 \mathrm{~L} 4$.

- Vertical injection molding machine

- Injection molds (fig. IC)

- Material shrinkage study

- Tapered core pins (Fig. IC)

- Establish the molding process

- Time required to become fully operational

- Cost per connector (SA/442-2 and S1457-1) in quantities of 100 or more

3. PEEK (RTP 2205)

- same as number two above

Sincerely,

Q.R.7.Baca

J. R. F. Baca

Division 2551 
JRFB:2551:ve

Distribution:

2550 D. W. Doak

2551 D. E. Carnicom

2551 J. R. F. Baca 

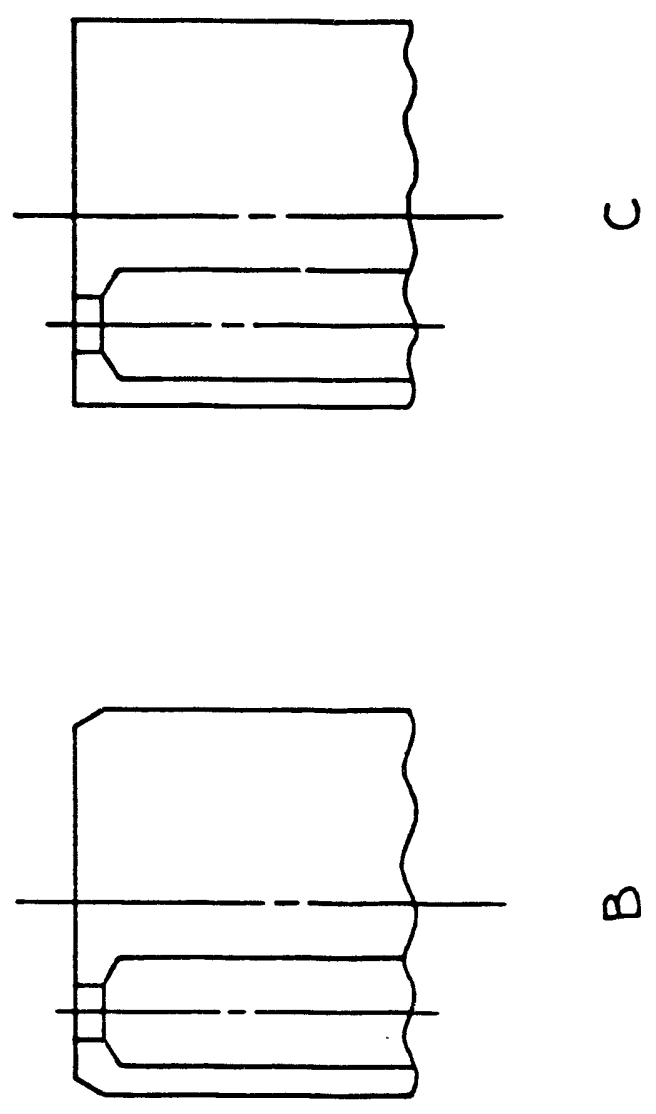

$\frac{-}{u}$

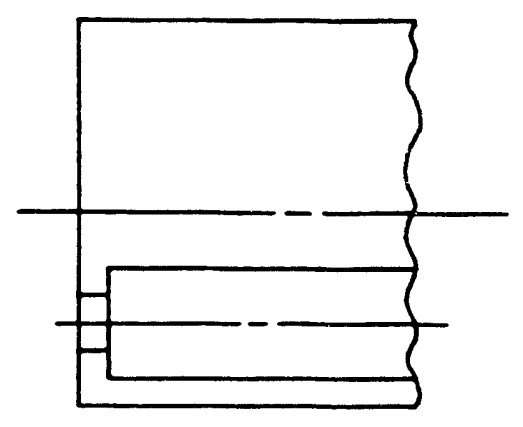

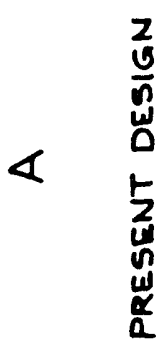


APPENDIX $J$

\section{BCO Material Evaluation Report}




\begin{tabular}{|c|c|c|}
\hline & REPORT NO. $C$ & 1049 \\
\hline & $\begin{array}{c}\text { AEPORT DATE } \\
12 / 18 / 90\end{array}$ & PAGE 1 of 5 \\
\hline Bendix Connector Operations & \multicolumn{2}{|c|}{ Sidney, Now York 13838-1395 } \\
\hline \multirow[t]{2}{*}{ MATERIAL EVALUATION } & \multicolumn{2}{|c|}{ EVALUATION } \\
\hline & $\begin{array}{l}\text { PROJECT NO. } \\
\text { (Contract) }\end{array}$ & $70821 \mathrm{~K}$ \\
\hline
\end{tabular}

C: J.R.F. Baca, A. Schildkraut, J. Badolato

\section{PURPOSE:}

To identify and insert material(s) for both hermetic and non-hermetic connectors, for the JT/LUT family, which will exhibit improved resistance to damage such as chipping, cracking, etc. The connectors must continue to meet the requirements, as defined, in Sandia

National Lats specifications for the SA1457 (hermetic) and SA1442 (non-hermetic) connectors. CONCLUSIONS:

1) Unchamfered inserts of Torion (hermetic) and PPS (non-hermetic) appear to have provided the best resistance to damage.

2) Chamfered inserts of all materials tested except the standard (blue and brown Fiberite: provided good resistance to damage.

3) The standard materials provided better resistance to damage in the chamfered configu- 1 ration than the unchamfered configuration.

4) Molding trials with Torlon and Fiberite E264H in the non-hermetic configuration were unsuccessful due to the high pressures required which damaged the molded-in contacts.

\section{RECOMMENDATIONS:}

1) Due to the problem of cracked/chipped inserts to socket contact inserts when used in receptacle connectors, consider the change to:

a) restricting pin contacts to receptacle connectors

b) redesign connector receptacles as hard mounting plug (plug connectors that mount in existing receptacle panels)

2) Consider an investigation of thermal plastic insert materials aimed at evaluating those with high flexural strength rather than high impact strength.

3) Consider alternative methods of molding inserts to prevent damage to molded-in contacts. such as: a) a multistep process so that shorter sections of unsupported contacts are exposed to the compound flow or b) a loose assembly of contacts and insulator which is over-molded with a tough material creating solid insert. 
Amphenol Corporation

Bendix Connector Operations

Sidney, New York 13838-1395

\begin{tabular}{|ll}
\hline REPORT NO. & C1-1049 \\
\hline Page & 2
\end{tabular}

RESULTS:

1) Due to manufacturing problems with E264H and Torlon for non-hermetic connectors, we substituted 16612 (green) and PPS (black) respectively. PPS is fortron, 1140L4.

2) The PPS material which is a thermoplastic material, required modified molding techniques which had to be produced in our Materials Lab (for non-hermetic only).

Other than the standard material for the non-hermetic connectors, the molding pressures are so great as to cause the berillium copper socket to bend/break in the molds.

\section{DETAILED REPORT:}

The following connectors were manufactured: (all are LJTO7 types 17-26S arrangement)

(SA1442-2)

Non-Hermetic

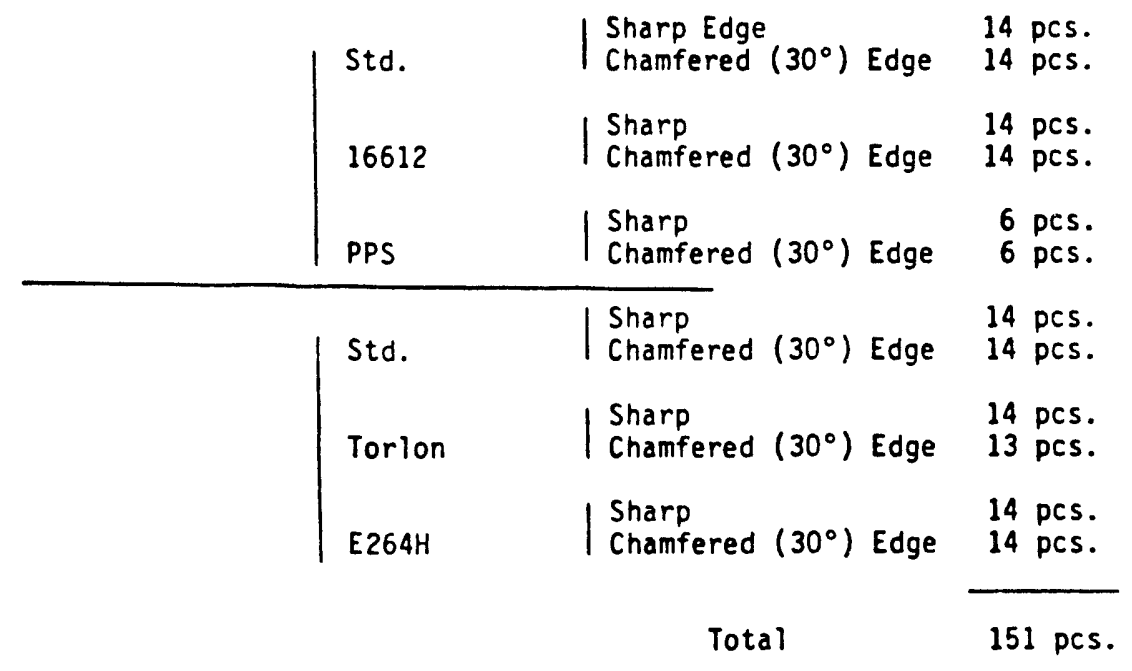

SEE SHEET 4 FOR BCO PART NUMBERS.

All connectors were subjected to the following tests, in order shown:

A) 1. Dielectric Withstanding Voltage

2. Insulation Resistance

3. VEECO (leak test)

4. Visual examination of inserts after successfully passing the above six $(6)$, ( 3 pcs. in the case of PPS) of connectors were tested as follows: 


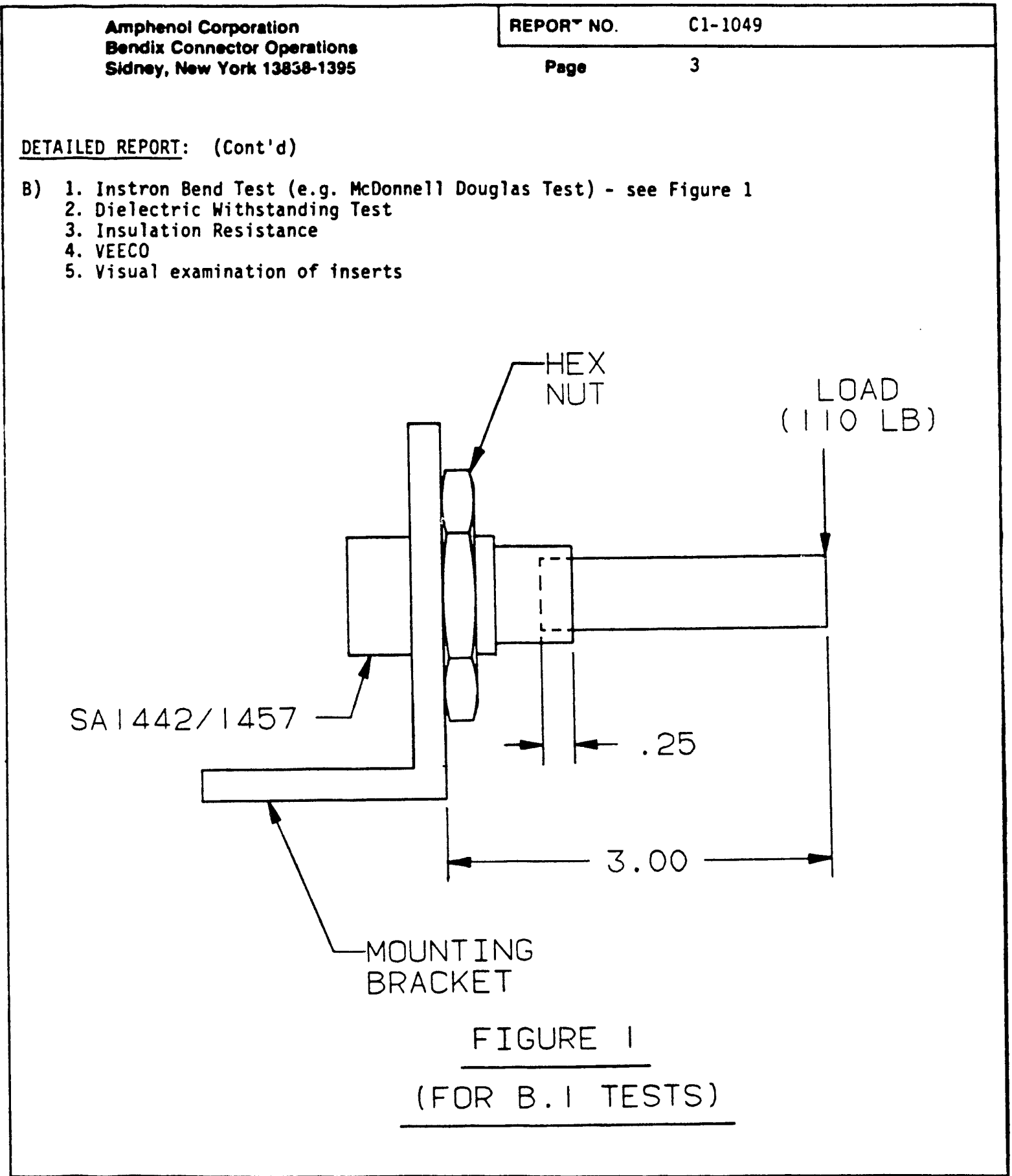




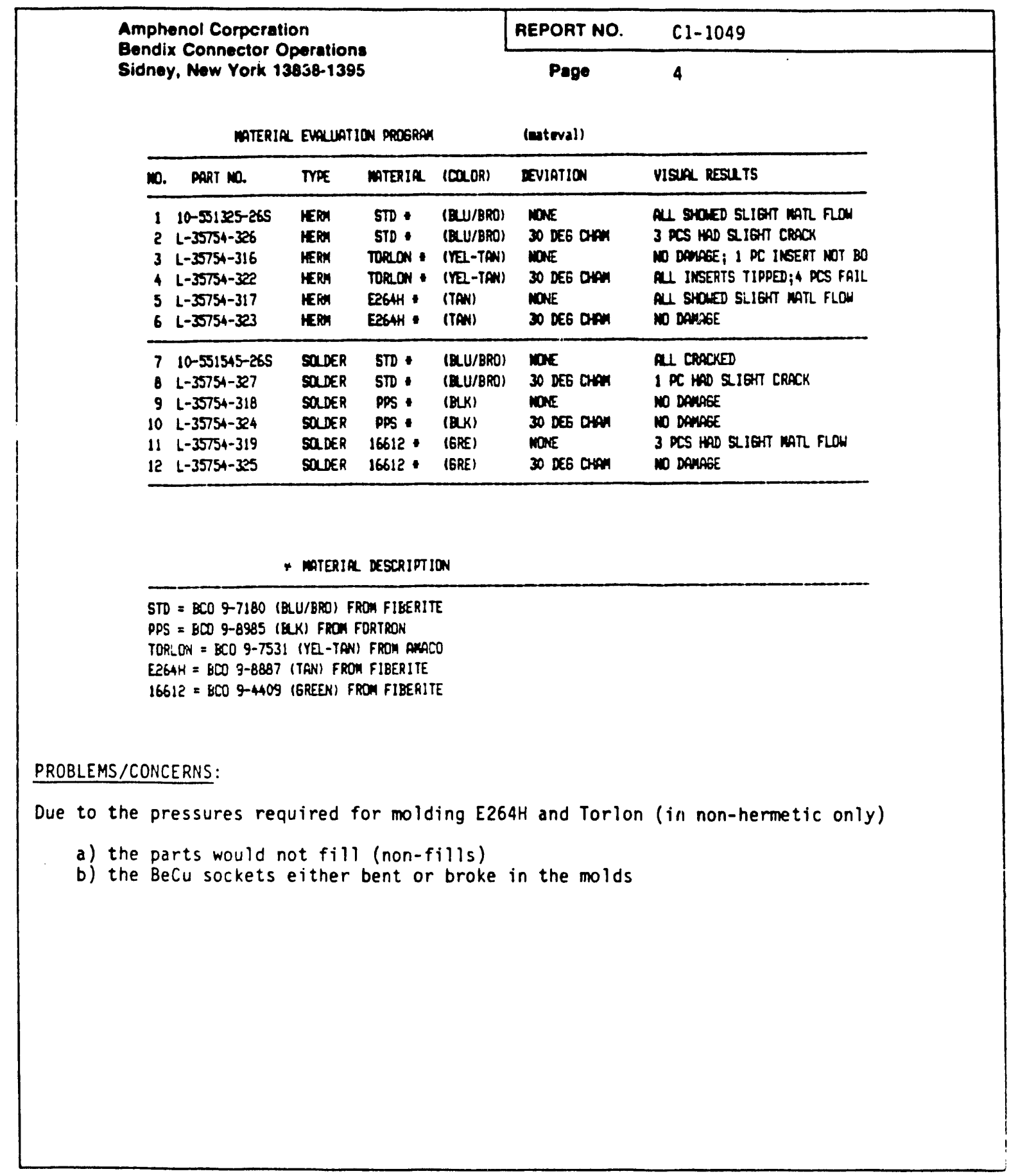




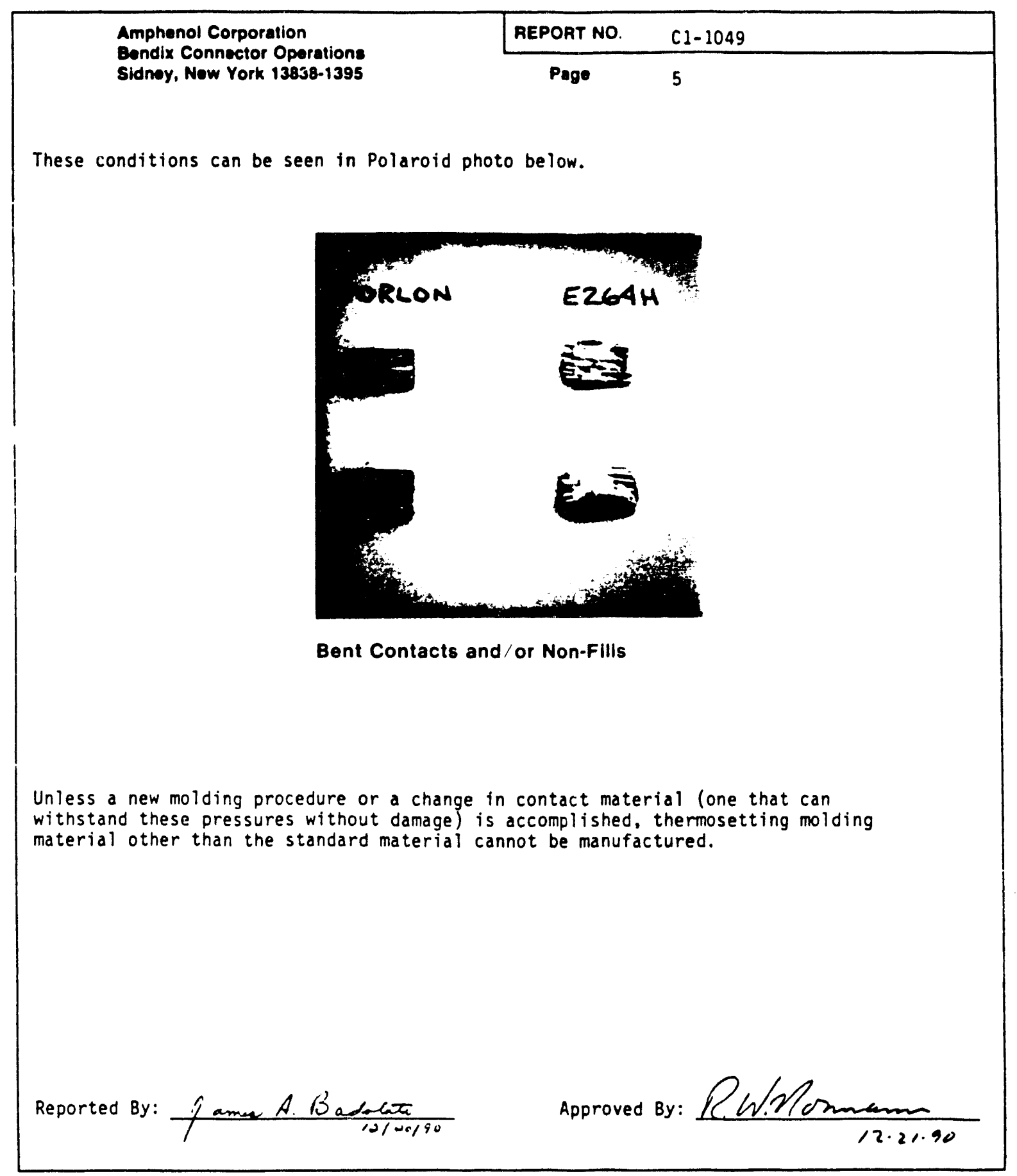




\section{DISTRIBUTION:}

10 Allied-Signal Aerospace Co.

Kansas City Division

Attn: D. R. Lemon, D457

D. K. Church, D457

C. A. Maschler, D457

H. F. Darbyshire, D864

R. G. Gemeinhardt, D864

D. R. Brunswick, D864

R. K. Bornkessel, D844

R. C. Harnden, D844

F. C. Goodale, D846

C. U. Fotopoulos, D846

PO Box 419159

Kansas City, MO 64141-6159

4 Amphenol Corp., BCO

Attn: A. L. Schildkraut

J. A. Badolato

J. B. Becker

R. G. Wheeler

40-60 Delaware St.

Sidney, NY 13838-1395

1 ICI Fiberite

Fiberite Molding Materials

Attn: Marty Choate

W. D. Williams

J. T. Love

J. A. Sayre

K. B. Wischmann

G. N. Beeler

R. S. Urenda

W. R. Nance

D. W. Doak

D. E. Carnicom

L. A. Andrews

J. R. F. Baca

M. J. Craig

R. D. Holt

P. J. Konnick

T. R. Perea

T. C. Cannon

L. K. Grube

M. R. Sjulin

R. R. Evans

D. L. McCoy

A. Hachigian

Central Technical Files

3141

3145

S. A. Landenberger

Document Processing

For DOE/OSTI

G. C. Claycomb 

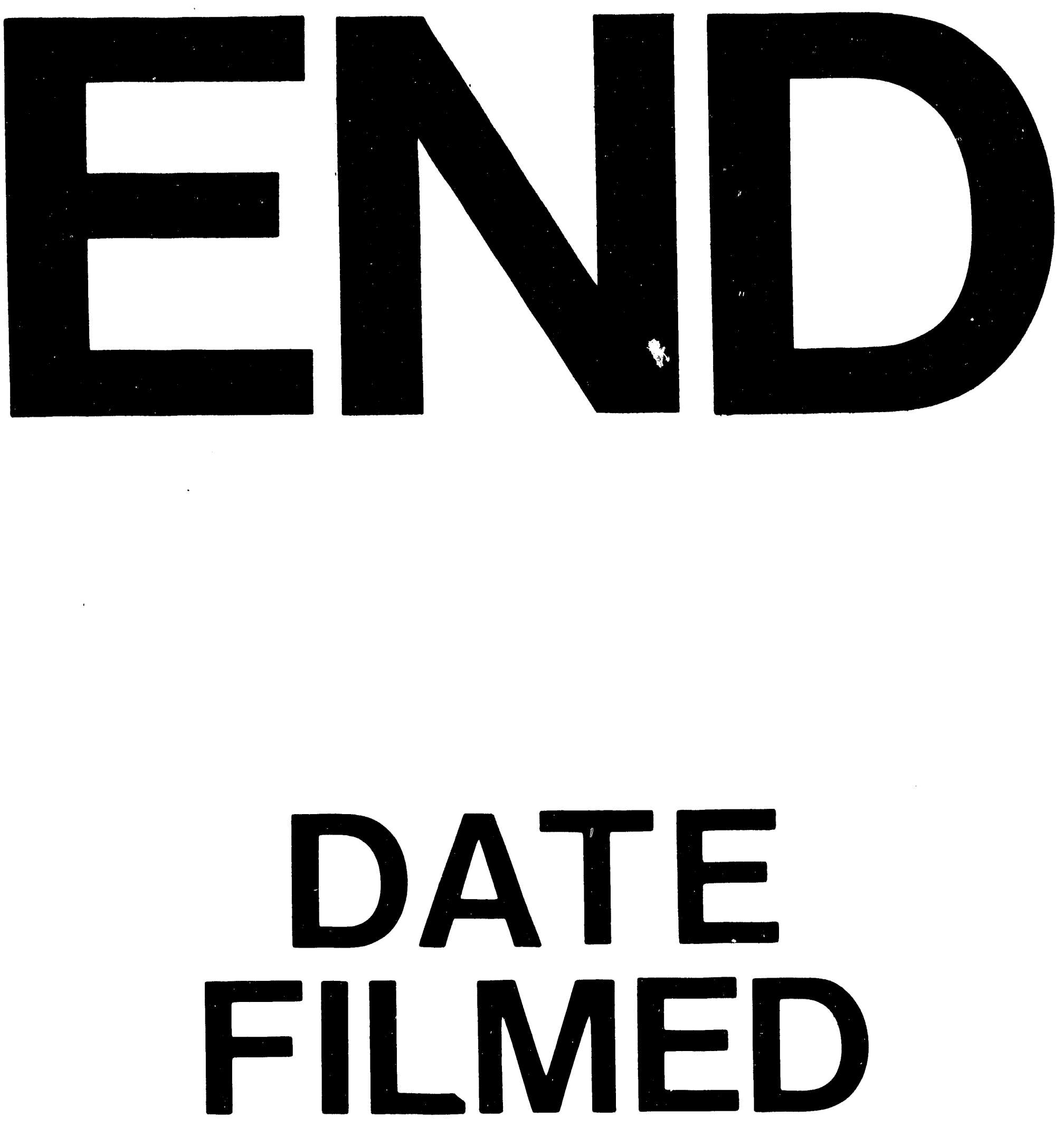

I

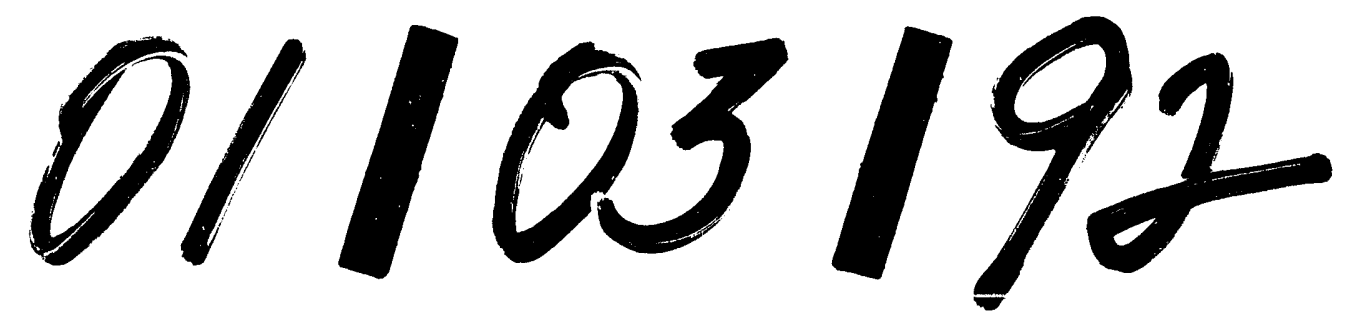


